\title{
1 An Overview of Zeolite, Zeotype and Mesoporous Solids Chemistry: Design, Synthesis and Catalytic Properties
}

\section{Thomas Maschmeyer and Leon van de Water}

Laboratory of Advanced Catalysis for Sustainability, School of Chemistry - F11, The University of Sydney, NSW 2006, Australia

\section{CONTENTS}

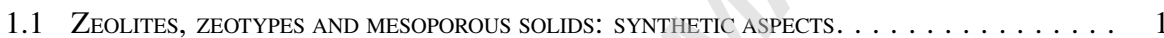

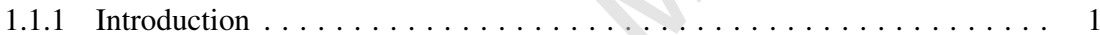

1.1.2 Synthetic aspects: template theory for zeolite synthesis . . . . . . . . 2

1.1.3 Synthetic aspects: template theory for mesoporous oxides synthesis . . . . 7

1.2 DESIGN OF EXTRA-LARGE PORE ZEOLITES AND OTHER MICROPOROUS AND MESOPOROUS CATALYSTS 11

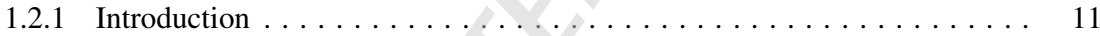

1.2.2 Extra-large pore zeolites $\ldots \ldots \ldots \ldots \ldots \ldots \ldots \ldots \ldots \ldots \ldots \ldots \ldots$

1.2.3 Hierarchical pore architectures: combining microporous and mesoporosity 13

1.3 POTENTIAL OF POST-SYNTHESIS FUNCTIONALIZED MICROPOROUS AND MESOPOROUS SOLIDS

AS CATALYSTS FOR FINE CHEMICAL SYNTHESIS . . . . . . . . . . . . . . . . . . . . . . . 19

1.3.1 Introduction . . . . . . . . . . . . . . . . . . . . . 19

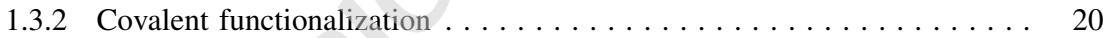

1.3.3 Noncovalent immobilization approaches . . . . . . . . . . . . 25

1.3.4 Single-site catalysts inspired by natural systems . . . . . . . . . . . . 29

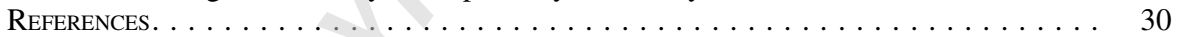

\subsection{ZEOLITES, ZEOTYPES AND MESOPOROUS SOLIDS: SYNTHETIC ASPECTS}

\subsubsection{INTRODUCTION}

The role that porous catalytic solids play in the production of a diverse range of everyday items, such as plastics, washing powders, fuels or pharmaceuticals, can hardly be overestimated. However, not all manufacturing processes rely on catalytic

Catalysts for Fine Chemical Synthesis, Vol. 4, Microporous and Mesoporous Solid Catalysts Edited by E. Derouane

(C) 2006 John Wiley \& Sons, Ltd 
technology at every step. Particularly fine chemicals and pharmaceuticals synthesis still employ classic stoichiometric approaches to a significant extent. Therefore, the development of new catalysts with even better characteristics in terms of activity, selectivity and stability is an on-going challenge. Initially, we will address the principles underlying the preparation of catalytically relevant microporous and mesoporous oxidic materials. Subsequently several sections deal with the various methods currently available to modify as-synthesized materials into single-site catalysts with well-defined properties.

Porous oxide catalytic materials are commonly subdivided into microporous (pore diameter $<2 \mathrm{~nm}$ ) and mesoporous $(2-50 \mathrm{~nm}$ ) materials. Zeolites are aluminosilicates with pore sizes in the range of $0.3-1.2 \mathrm{~nm}$. Their high acidic strength, which is the consequence of the presence of aluminium atoms in the framework, combined with a high surface area and small pore-size distribution, has made them valuable in applications such as shape-selective catalysis and separation technology. The introduction of redox-active heteroatoms has broadened the applicability of crystalline microporous materials towards reactions other than acid-catalysed ones.

Since mesoporous materials contain pores from $2 \mathrm{~nm}$ upwards, these materials are not restricted to the catalysis of small molecules only, as is the case for zeolites. Therefore, mesoporous materials have great potential in catalytic/separation technology applications in the fine chemical and pharmaceutical industries. The first mesoporous materials were pure silicates and aluminosilicates. More recently, the addition of key metallic or molecular species into or onto the siliceous mesoporous framework, and the synthesis of various other mesoporous transition metal oxide materials, has extended their applications to very diverse areas of technology. Potential uses for mesoporous 'smart' materials in sensors, solar cells, nanoelectrodes, optical devices, batteries, fuel cells and electrochromic devices, amongst other applications, have been suggested in the literature. ${ }^{[1-5]}$

\subsubsection{SYNTHETIC ASPECTS: TEMPLATE THEORY FOR ZEOLITE SYNTHESIS}

Aluminosilicate zeolites have been produced synthetically since the 1950s. In the 1960s tetraalkylammonium ions were added to zeolite synthesis gels, resulting in the synthesis of new structures such as the ZSM-5 family of zeolites. ${ }^{[6]}$ "Template Theory' evolved to explain the structure-directing effects of organic species in zeolite synthesis gels. ${ }^{[7]}$ Charge distribution, size and geometric shape of the template species were believed to be the main causes of the structure-directing process. Factors such as $\mathrm{pH}$, concentration, $\mathrm{SiO}_{2} / \mathrm{Al}_{2} \mathrm{O}_{3}$ ratio, ageing, agitation and temperature were considered to be the main determinants of the gel chemistry that influence the outcome of the zeolite crystallization process. However, addition of organic template species affected the gel chemistry of zeolite synthesis mixtures also and it was not clear which factors dominated, template activity or gel chemistry, in the determination as to which product formed. ${ }^{[8]}$ Although at first glance it may have appeared that there was a good correlation between template 
structure and pore architecture, the development of new synthetic procedures for making zeolites using organic templates has been, and still is, conducted chiefly by trial and error. ${ }^{[9]}$

Generally, zeolite synthesis mixtures contain a silicon (and aluminium) precursor, a template species (alternatively called structure-directing agent, SDA) which can be either an organic species or an alkali metal ion, water, and a so-called mineralizing agent. This mineralizing agent, usually $\mathrm{OH}^{-}$, or $\mathrm{F}^{-}$in some more recent studies, ${ }^{[10]}$ leads to the partial dissolution of any silica network formed, thereby making the zeolite formation process reversible and steering it away from very unstable structures for any given set of synthesis conditions. This is important as less regular phases and phase mixtures would otherwise be the result. The relation between SDA and the framework structure formed has been thoroughly investigated. For example, the group of Zones and Davis systematically probed the effect of rigid, bulky organocationic SDAs on the final zeolite structures obtained. ${ }^{[11]}$ The SDAs were designed to destabilize the structure of commonly occurring competing phases, and three new zeolitic phases were indeed reported from this study. Molecular modelling confirmed the correlation between the structure of the SDA and that of the observed zeolite phase. However, in contrast to the results from this study, it is in most cases not possible to derive a one-to-one relationship between template and framework structure. Despite the progress made, the question why certain templates induce certain zeolite structures still remains largely unanswered, especially in the case of the smaller, less rigid tetraalkylammonium templates. Zeolite crystallization appears largely kinetically controlled, which means that instead of the thermodynamically most stable product often the species that nucleates most easily is formed. ${ }^{[9]}$ Therefore, the term 'template' should be used only in those cases where a true one-to-one relationship between organic species and inorganic framework structure exists. Often, one might view the 'template' rather acting as a crystal growth moderator (nucleation and/or retardation) than as a true template.

The development of the understanding of the underlying principles of zeolite synthesis has been reviewed recently by Cundy and Cox. ${ }^{[12]}$ The initial stages of the organization of the silica precursor around the template molecules have been studied by many authors. In most cases, the tetrapropylammonium hydroxide (TPAOH)-tetraethoxy silane (TEOS)-water system has been the subject of these fundamental studies. Burkett and Davis ${ }^{[13,14]}$ described the organization of the silicon source and the organic template species as the result of van der Waals interactions, where hydrophobic alkyl chains of the template and hydrophobic silicon atoms closely interact. It is proposed that an organized, hydrophobic water layer is formed around the alkyl chains, which can be considered as an organized hydration mantle (Figure 1.1).

A similar organized solvent mantle is proposed to be present around the silicate species and a displacement of the hydration mantle around the SDA by the silicate species is the origin of the SDA-silicate interaction. Long-range order is attained in a consecutive layer-by-layer zeolite growth step. This proposed formation mechanism is in agreement with results of an in situ SAXS and WAXS study by de Moor et al. ${ }^{[15]}$ of the same system. Their results show the initial formation of colloidal 

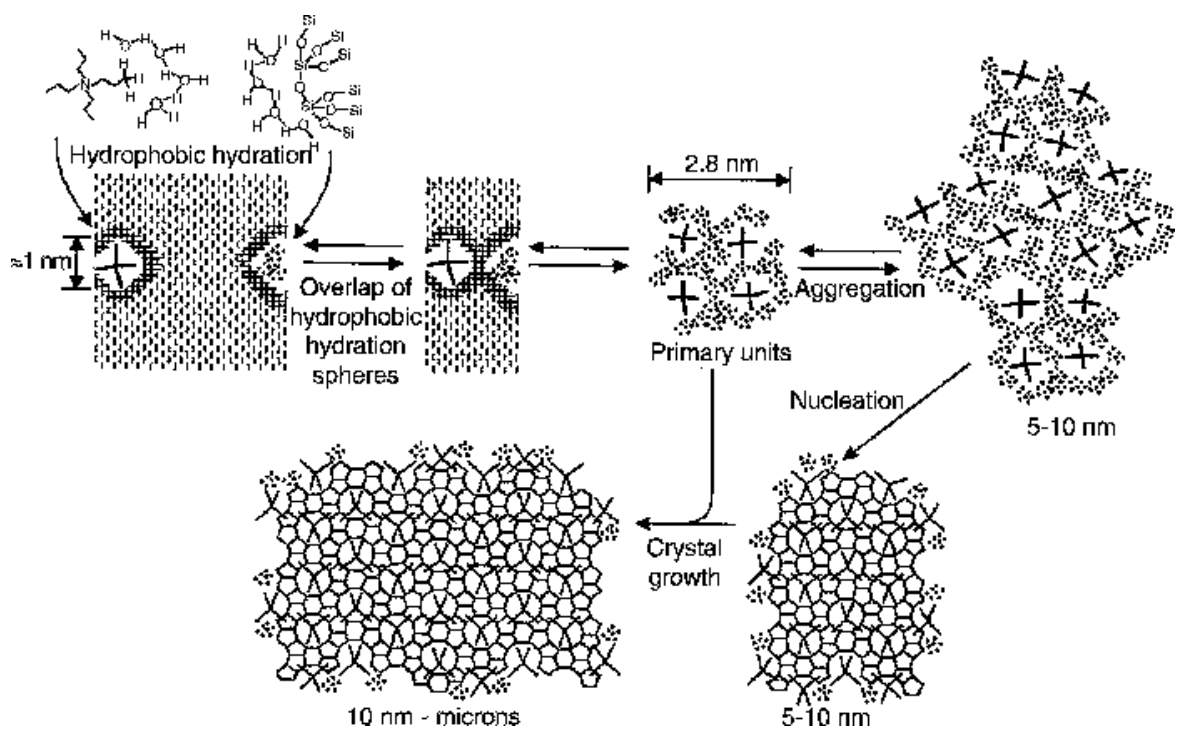

Figure 1.1 Scheme for the crystallization mechanism of Si-TPA-MFI. Reproduced from Corma and Davis ${ }^{[28]}$ by permission of Wiley-VCH

amorphous aggregates, which are not organized further in a secondary aggregation step, but instead, redissolve and act as a source of nutrients for the growing crystallites. It was also found that the alkalinity of the clear synthesis gel solution plays an important role in the size of the final crystal: at higher alkalinity a smaller number of viable nuclei are being formed, giving rise to larger crystals. In contrast to this formation mechanism, other authors have suggested the formation of small, highly organized silicate-SDA clusters, so-called secondary building units, a concept already proposed by one of the founding fathers of zeolite chemistry. ${ }^{[16]}$ According to the research group in Leuven, these building blocks form during the earliest stages of zeolite preparation, i.e. already during the mixing of the silicon precursor, the TPAOH template and water at ambient temperature and pressure. These precursor species, with dimensions of $1.3 \times 4.0 \times 4.0 \mathrm{~nm}$ ('nanoblocks' or 'nanoslabs'), contain features specific for the MFI structure, as was concluded from IR data. ${ }^{[17]}$ It was also found that this species contains TPA in the channel intersections. In a subsequent paper the same authors show, on the basis of a ${ }^{29} \mathrm{Si}$ NMR study, that TPA cations are present at the liquid-liquid TEOS-water interface, with their propyl chains pointing into the TEOS layer. ${ }^{[18]}$ The hydrolysis-condensation reactions of the TEOS molecules require close contacts with the template, indicating that the structure direction by the template and the hydrolysis take place simultaneously. Initially, tetracyclic undecamers are formed, and after $45 \mathrm{~min}$ at room temperature trimers of this entity (i.e. 33-mers) were observed (Figure 1.2). This species contains hydroxyl groups on its outer surface, allowing migration into the aqueous layer. ${ }^{[18]}$ Aggregation of these building blocks occurs very slowly due to electrostatic repulsion between the negatively charged silicate entities. This charge 
(a)

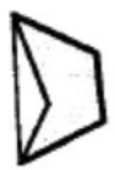

(b)

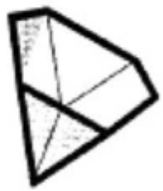

(c)

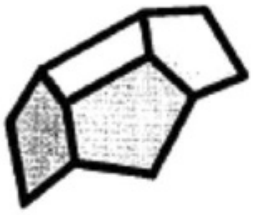

(d)

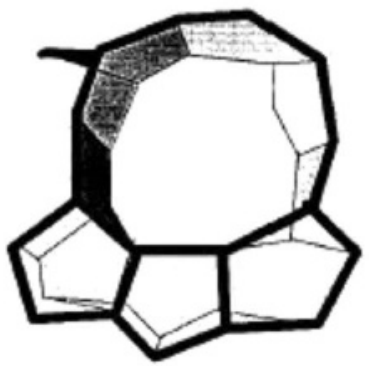

(e)

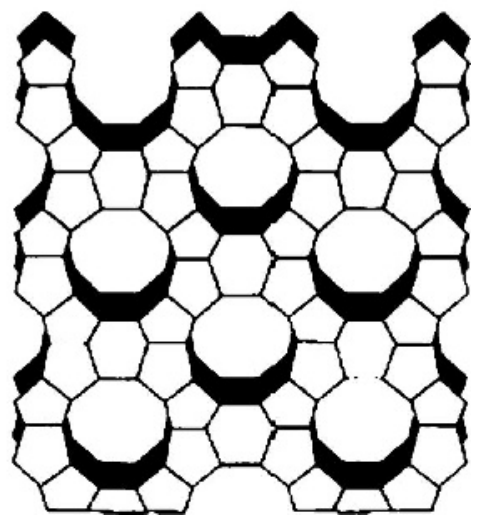

Figure 1.2 Siliceous entities occurring in the TPAOH-TEOS system: (a) bicyclic pentamer; (b) pentacyclic octamer; (c) tetracyclic undecamer; (d) 'trimer' in mixtures with composition $(\mathrm{TPAOH})_{0.36}(\mathrm{TEOS})\left(\mathrm{H}_{2} \mathrm{O}\right)_{6.0}$, (e) nanoslab in mixtures with composition $(\mathrm{TPAOH})_{0.36}(\mathrm{TEOS})\left(\mathrm{H}_{2} \mathrm{O}\right)_{17.5}$. Reproduced from Kirschhock et al., J. Phys. Chem. B, 1999, 103, 4972-4978 by permission of American Chemical Society 
is compensated by the $\mathrm{TPA}^{+}$template species, which explains their structuredirecting effect upon condensation of the zeolite framework around it.

$\mathrm{Bu}$ et al. investigated the role of methyl amine as the organic template in thesynthesis of a series of zeotype germanates. In the absence of the template a two-dimensional layered structure was formed. In contrast, in the presence of methylamine a three-dimensional framework evolved from these sheets. ${ }^{[19]}$

The presence of (quaternized) amines is not a prerequisite for the formation of a zeolite. Some zeolites can be prepared by using an alkali metal ion species as the SDA, examples being zeolites $\mathrm{A}, \mathrm{X}$, and $\mathrm{Y}$ (for details see International Zeolite Association website, http://www.izasynthesis.org/). The formation mechanism of these zeolites has not been investigated in great detail. Atomic force microscopy (AFM) was used to study the role of defects on the growth process of zeolites Y, A, and Silicalite-1. ${ }^{[20]}$ It was found that the surface of the growing crystals in zeolite $\mathrm{Y}$ is composed of terraces with a height of $15 \AA$, corresponding to the height of a faujasite sheet. Similarly, a terrace height of $12 \AA$ was observed for zeolite A, which corresponds to the size of a sodalite cage. These observations have been explained by assuming a layer-by-layer growth process, where template ions decorate the surface of the negatively charged growing zeolite crystal. However, the role that alkali metal ions play in the growth process was not elucidated in this study. This 'terraceledge-kink' growth mechanism is in agreement with a study by Bosnar et al. ${ }^{[21]}$ who investigated the role of $\mathrm{Na}^{+}$concentration on the growth rate of zeolite A. It was found that the $\mathrm{Na}^{+}$ions take part in the surface reaction by balancing the surface charge. The growth rate was found to increase with increasing $\mathrm{Na}^{+}$concentration.

It is clear that for a better understanding of the zeolite formation mechanism, in situ characterization techniques are essential. The aforementioned studies involve in situ IR, ${ }^{29} \mathrm{Si}$ NMR and X-ray scattering techniques, ${ }^{[13-15,17]}$ although only the gel stage of the zeolite formation process was covered in these cases. The next step is the study of the crystallization process for these microporous materials, and indeed several research groups have reported such in situ investigations. ${ }^{[15,22,23]}$ Unfortunately, only one analytical technique was used in each of these studies, which makes it difficult to obtain information on all aspects of the crystal growth process. Very recently, Grandjean et al. reported the combination of multiple time-resolved in situ techniques, namely SAXS-WAXS, UV-vis, Raman and XAS, for probing the crystallization of a cobalt-modified aluminophosphate material, Co-APO-5. ${ }^{[24]}$ This study showed that the alumina and phosphoric acid precursors react instantaneously after mixing to form Al-O-P chains (Raman data). These largely covalent polymeric structures are then thought to agglomerate, in a similar way to the nanoslabs as introduced by Ravishankar et al. ${ }^{[17]}$ and Kirschhock et al. ${ }^{[18]}$ In the Co-APO-5 study it was shown that the size of these primary particles increases from $7 \mathrm{~nm}$ in the very beginning of the heating process to $20 \mathrm{~nm}$ just before the start of the crystallization. The coordination number of about half of the $\mathrm{Co}^{2+}$ ions in the mixture changes slowly from 6 to 4 in the heating stage prior to crystallization (EXAFS data). The crystallization abruptly begins at around $155-160{ }^{\circ} \mathrm{C}$, which was derived from the rapid transformation of the remaining octahedral $\mathrm{Co}^{2+}$ to tetrahedral coordination, as observed with EXAFS and UV-vis spectroscopies. 
However, the structure-directing effect of the template on the final framework structure was not elucidated even in this study. In situ studies into the structural features of the template species at the gel stage and during crystallization are needed to shed more light on this issue.

In recent years, some progress has been made in understanding zeolite templating by using computer modelling. Attempts have been made to predict the templates required for certain zeolite syntheses by Lewis et al. ${ }^{[25,26]}$ Both known templates and a new one, which was subsequently proven experimentally to direct a certain zeolite structure, were generated by the model. However, the interactions between template and silicate host are often more complex than this space-filling approach assumes and further fine-tuning is needed. ${ }^{[9]}$

The zeolite framework type that is formed during hydrothermal treatment is not only a function of the applied SDA. The introduction of heteroatoms other than silicon or aluminium in the framework may stabilize certain structural features, thereby allowing the formation of zeolite structures that are not attainable otherwise. Blasco et al. used Hartree-Fock $a b$ initio methods to discover that the presence of small amounts of $\mathrm{Ge}^{4+}$ in the silica framework stabilizes double fourmembered rings (D4MR), cubic subunits formed by two rings each containing four silicon atoms. ${ }^{[27]}$ D4MR are absent in most known silicate frameworks, ${ }^{[28]}$ as the strain present in this arrangement makes them highly unstable. By replacing some of the $\mathrm{Si}-\mathrm{O}-\mathrm{Si}$ linkages by $\mathrm{Si}-\mathrm{O}-\mathrm{Ge}$, some of the strain can be released. This stabilizing effect has been successfully applied by the same authors to synthesize a hitherto unknown polymorph of zeolite Beta, polymorph $\mathrm{C}$, which can only be made by introducing a germanium precursor to the synthesis gel. ${ }^{[29]}$ This study shows that in some cases computational techniques can be successfully applied to predict the beneficial effect of this type of isomorphous substitution.

\subsubsection{SYNTHETIC ASPECTS: TEMPLATE THEORY FOR MESOPOROUS OXIDES SYNTHESIS}

Mesoporous oxides are formed in the presence of surfactant-type template molecules. These species form micelle aggregates in aqueous environments. The organization mechanism of the monomeric silica species around these 'micellar rods' was coined the 'Liquid Crystal Templating' (LCT) mechanism. Subsequent hydrothermal treatment and calcination leads to condensation of the silica species and removal of the organic template species, respectively. The concurrent discovery of M41S materials by Mobil scientists in 1992 and the discovery of the very similar material FSM-16 (formed by recrystallization of kanemite after ion exchange of the $\mathrm{Na}^{+}$ ions for tetraalkyl ammonium ions) by Inagaki et al. in 1994 mark the beginning of the new era of well-defined, periodic mesoporous oxides. ${ }^{[30-33]}$ A great deal of work has been directed towards refining the dilute regime synthetic procedure and improving the properties of the resulting mesoporous materials since. Mesoporous materials are generally synthesized at low temperatures $\left(25-100{ }^{\circ} \mathrm{C}\right)$ so that the condensation reactions are predominantly kinetically controlled. ${ }^{[34]}$ The silica 
mesopore walls in these materials are amorphous on an atomic scale, which means that they are thermodynamically less stable than the metastable zeolite frameworks. Quartz is thermodynamically the most stable form of silica and prolonged high temperature heating of either mesoporous silica or all silica zeolites would eventually lead to its formation.

In the original papers describing the synthesis of M41S materials, ${ }^{[30,31]}$ the pore diameters of the mesoporous materials were determined by the choice of surfactant template, and also by the use of an auxiliary organic molecule, mesitylene $(1,3,5-$ trimethylbenzene). Pore diameters ranging between 20 and $100 \AA$ were obtained. Further investigations by the same research group revealed that with the same synthesis, different mesophases could be produced. Apart from MCM-41, which forms around rod-like micellar surfactant aggregates, a cubic phase with a threedimensional pore system, MCM-48, was observed when a spherical organization of the surfactant species, instead of a rod-like one, occurs. It was reported that the surfactant to silica ratio was the crucial parameter in determining the shape of the micelle aggregates. ${ }^{[35]}$ More recently, $n$-alkanes of different chain lengths were used as swelling agents for the mesoporous products. ${ }^{[36]}$ The pore diameters of the products increased proportionally with the length of the $n$-alkanes, containing up to 15 carbon atoms. The pore diameter of mesoporous products has also been controlled by adjusting the synthesis gel and crystallization variables. In the presence of tetramethyl ammonium cations, mesoporous products were formed after $24 \mathrm{~h}$, and the pore size increased with longer crystallization times. ${ }^{[37]}$ Similar results were obtained by Cheng et al., where the pure silica MCM-41 channel diameter was varied between 26.1 and $36.5 \AA$, and the wall thickness was varied between 13.4 and $26.8 \AA$, simply by using different synthesis temperatures $\left(70-200{ }^{\circ} \mathrm{C}\right)$ and/or reaction times. ${ }^{[38]}$ In general, MCM-41 with wider pores, thicker walled channels and higher degrees of polymerization were obtained for longer reaction times. The MCM-41 structure with the thickest walls ( $26.8 \AA$ ) could withstand temperatures as high as $1000^{\circ} \mathrm{C}$ without disintegration. The suggested explanation for the pore expansion with increasing reaction time was as follows: as reaction times are increased, the pore size of the MCM- 41 product increased, reaching an upper limit very close to the diameter of a cetyltrimethyl ammonium bromide (CTAB) micelle. At high temperatures $\left(165^{\circ} \mathrm{C}\right.$ in the work of Cheng et al.), some surfactant cations decompose to neutral $\mathrm{C}_{16} \mathrm{H}_{33}\left(\mathrm{CH}_{3}\right)_{2} \mathrm{~N}$ molecules, which locate themselves in the hydrocarbon core of the micelle. This has the effect of increasing the micelle diameter, and therefore the MCM-41 pore size. There is, however, an upper limit to the number of neutral amine molecules the micelles can accommodate in their core, leading to an upper limit in the swelling effect. ${ }^{[38]}$

Particle size is of particular importance for mesoporous materials containing unidirectional channels, such as MCM-41. If the mesopores are long, which might be the case in large particles, diffusion limitations could occur and in these cases it is preferable to have a very small particle size. Small particles of MCM-41 are obtained if reaction times are kept short, i.e. the mesoporous product nucleates, but has little time to grow into larger particles. Cutting the reaction times short can, however, jeopardize the silica condensation process, leading to poorly polymerized 
products. Microwave heating overcomes this problem by speeding up the condensation step, allowing high quality products to form in times as short as $1 \mathrm{~h}$ at $150{ }^{\circ} \mathrm{C} \cdot{ }^{[39-42]}$ The resulting MCM-41 crystallites are very small (approximately $100 \mathrm{~nm}$ in diameter).

Virtually at the same time as M41S mesoporous silicas were first being synthesized, Inagaki et al. ${ }^{[32,33]}$ reported the synthesis of hexagonally packed channels from layered polysilicate kanemite. The mechanism for the formation of this material, FSM-16, is very different from the silicate anion-initiated MCM-41 synthesis and has been shown to occur via intercalation of the kanemite layers with surfactant molecules. Kanemite consists of flexible, poorly polymerized silicate layers which buckle around the intercalated surfactant molecules. Vartuli et al. ${ }^{[43]}$ compared M41S materials generated from the ligand charge transfer (LCT) method with the products resulting from intercalation of layered polysilicates. Both methods used alkyl trimethylammonium surfactants as templates, but the mechanisms of formation, silicate anion initiated LCT and intercalation were very distinct. The MCM-41 synthesized using the LCT method was found to have five times the internal pore volume of the layered silicate-derived material, and the pore-size distribution was found to be sharper than for FSM-16.

Based on the same LCT mechanism, other mesoporous silicate materials have been developed since. Some of these newer materials have improved characteristics such as a higher thermal stability, which is known to be limited in the case of MCM-41. ${ }^{[44]}$ Apart from the low thermal stability, the one-dimensional pore structure of MCM-41 poses limitations to its applications. The field of mesoporous oxide materials was further extended by Pinnavaia and co-workers, who used nonionic poly(ethylene oxide) template molecules. ${ }^{[45]}$ The low cost and nontoxicity of this type of surfactant was reported to be the main advantage. The silica framework was formed around the rod- or worm-like micelles formed, where the channels in the three-dimensional structure showed diameters between 20 and $58 \AA$. More recently, in 1998, ultra-large pore hexagonal and cubic mesoporous products were synthesized using nonionic poly(alkylene oxide) triblock copolymers as structure directing agents and tetraalkoxysilane silica sources, in acidic media $(\mathrm{pH}<1) .{ }^{[46]}$ This work is related to the work reported by Pinnavaia's group, where the larger size of the structure-directing agent species allows pore sizes of up to $300 \AA$ in the products. The hexagonal SBA-15 product was synthesized with a wide range of uniform pore sizes and pore wall thicknesses at low temperature $\left(35-80{ }^{\circ} \mathrm{C}\right)$ using triblock copolymers, such as poly(ethylene oxide)-poly(propylene oxide)-poly(ethylene oxide), PEO-PPO-PEO. The method was found to be very versatile: structured products were obtained using (TMOS, TEOS and TPOS) as silica sources, and a whole range of acids were used to obtain the required synthesis gel pH ( $\mathrm{HCl}, \mathrm{HBr}, \mathrm{HI}, \mathrm{HNO}_{3}, \mathrm{H}_{2} \mathrm{SO}_{4}$ or $\left.\mathrm{H}_{3} \mathrm{PO}_{4}\right)$. More recently, the synthesis of SBA-15 materials has been conducted by the same authors in a confined environment, in porous alumina nanochannels. In contrast to synthesizing the material on flat surfaces, where thin films of two-dimensional mesostructures are formed, the confinement of the synthesis causes the sheets to roll up in the cylindrical space. Amongst other structural motifs, the resulting structures exhibit chiral (although 
racemic) double-helical channels. ${ }^{[47]}$ It was shown to be possible to modify the exact morphology by changing the dimensions of the alumina channels.

Following similar principles of combining the aggregate-forming properties of bifunctional molecules with low cost and low toxicity, a mesoporous silica material with a three-dimensional worm-like pore system was reported. Triethanol amine (TEA) was used as the SDA and TEOS as the silica source in this mesoporous silica, TUD-1. ${ }^{[4]}$ The formation mechanism is depicted in Figure 1.3(a). The properties of the material can be easily tuned by modifications in the synthesis procedure, for example, the pore size of the material was found to be proportional to

(a)<smiles>O[Si]12OCCN(CCO1)CO2</smiles>

Complexation

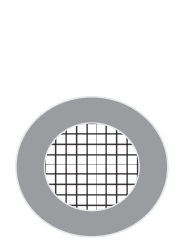

Particle growth

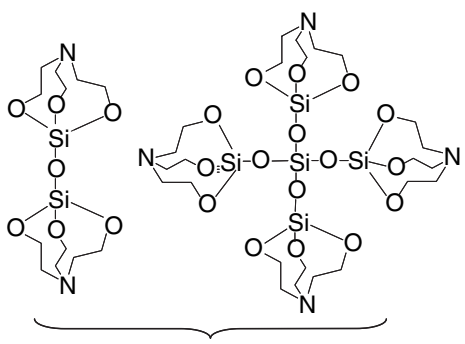

Condensation

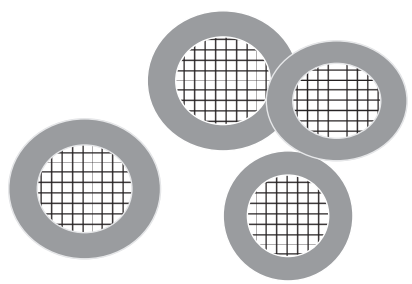

Aggregation

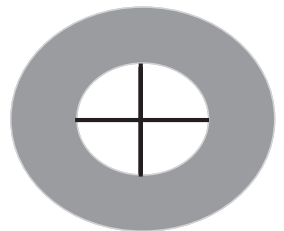

Initial nucleus

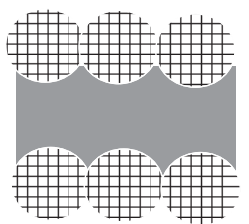

Micro-syneresis/Struct. Form.

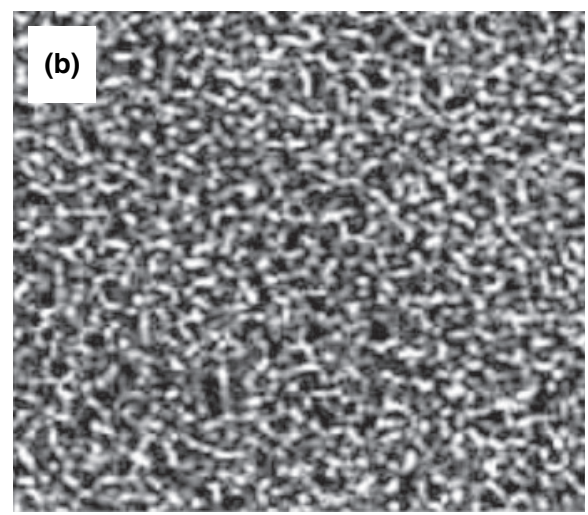

(c)

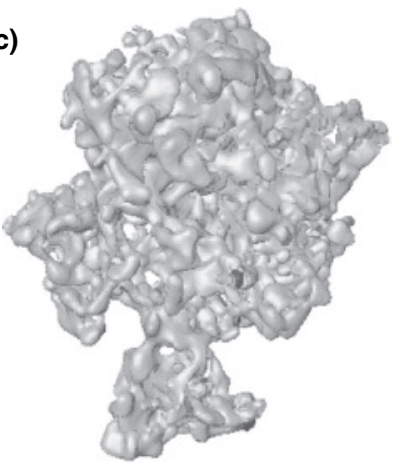

Figure 1.3 (a) TUD-1 synthesis path, grey shading indicates aggregation of TEA, hatched area indicates silica. (b) HR-TEM image of the mesoporous, foam-like structure. (c) threedimensional representation of TUD-1 particle, based on a series of HR-TEM images, created under the supervision of Prof. K. P. de Jong, Utrecht University, The Netherlands 
the hydrothermal heating time, and is typically in the range of $25-500 \AA{ }^{[49]}$ BET surface areas can be as high as $1000 \mathrm{~m}^{2} \mathrm{~g}^{-1}$, and the material exhibits a high thermal and hydrothermal stability. A high resolution transition electron microscopy (HR-TEM) image and a representation based on three-dimensional HR-TEM images of the material are also shown in Figure 1.3.

The field of mesoporous materials has developed rapidly since the first reports on these materials in 1992, as these last examples show. The trend is to utilize inexpensive, multifunctional micelle- or aggregate-forming surfactants or templates which may adopt many different liquid crystal-like configurations in aqueous solution. Formation of a silicate structure with well-defined pore dimensions and connectivity may then be accomplished by the appropriate choice of the synthetic conditions. Additional microporous and macroporosity may be incorporated by using macroporous host materials, as in the case of Stucky of the work by and coworkers, who created mesophases with unprecedented architecture. ${ }^{[47]}$

\subsection{DESIGN OF EXTRA-LARGE PORE ZEOLITES AND OTHER MICROPOROUS AND MESOPOROUS CATALYSTS}

\subsubsection{INTRODUCTION}

The utility of the currently available catalytic microporous and mesoporous oxide materials is limited by their attainable pore sizes, pore architectures, the uniformity of the structures and the extent to which catalytically active heteroatoms can be introduced. ${ }^{[28]}$ In the case of zeolites, the small size of the pores is the main limitation to their use in fine chemical or pharmaceutical synthetic applications, as most substrate and product molecules are too large to enter or leave the pore system. Also, in applications such as hydrocracking in oil refineries, the substrate species are often too large to make use of the internal surface of zeolite catalysts (other than in pore-mouth catalysis). Mesoporous materials, on the other hand, have as a main disadvantage their noncrystallinity, resulting in lower thermal and mechanical stability and in broader pore-size distributions and, hence, lower substrate/product selectivities compared with those found for zeolites. Moreover, the lack of crystallinity means a high concentration of structural defects, i.e. the presence of a high degree of surface silanol groups. For mesoporous aluminosilicates, an incomplete incorporation of aluminium into the framework and a less rigid lattice environment means that their acidity is considerably lower than for zeolites, which limits their use as acid catalyst in reactions with large substrate species. In the following sections, approaches to close the gap between zeolites and mesoporous materials as catalysts are discussed.

\subsubsection{EXTRA-LARGE PORE ZEOLITES}

A great demand exists for (hydro)thermally stable, crystalline structures with pore sizes in the $10-20 \AA$ size range that feature tetrahedral frameworks to allow 
incorporation of heteroatoms like $\mathrm{Al}$ to generate a framework charge imbalance and, thus, impart the material with a high acidic strength. ${ }^{[50]}$ Although some progress has been made in recent years, the crystallization of extra-large pore zeolites (containing 12-membered or larger rings) has been and continues to be a great challenge. Many of the reported extra-large pore crystalline structures are aluminophosphates, rather than silica-based materials. The first example of this class, VPI-5, was reported in 1988 and features one-dimensional channels with 18-membered rings (pore diameter of $12 \AA$ ). ${ }^{[51]}$ These aluminophosphates, however, often suffer from low thermal stability due to the presence of substantial amounts of terminal $\mathrm{OH}$ groups and extra-framework octahedral T-atoms. The extra-large pore $\mathrm{SiO}_{2}$ materials, UTD- $1,{ }^{[52,53]}$ CIT- $5^{[54]}$ and the germanosilicate IM$12,{ }^{[55]}$ which contains 12 - and 14-membered rings with internal free diameters of $8.5 \times 5.5 \AA$ and $9.5 \times 7.1 \AA$, all contain 14-membered rings in their largest channels, but the pore diameters of these materials do not exceed $10 \AA$. Corma et al. reported the crystallization of ITQ-15, containing a two-dimensional channel system of interconnected 12- and 14-ring channels (pore dimensions $8.4 \times 5.8 \AA$ and $10 \times 6.7 \AA$, respectively), ${ }^{[56]}$ and of ITQ-21, which contains a three-dimensional channel system of 12 -membered rings with a diameter of $7.4 \AA$ and cavities with a dimension of $11.8 \AA{ }^{[57]}$ These ITQ materials were tested in cracking experiments involving large substrate species and, indeed, they were found to exhibit higher activities than catalysts with smaller channel dimensions or lower pore dimensionality. In all these cases, however, very costly cationic ammonium species were used as the SDAs. The largest rings reported for silica-based materials are those of the thermally stable gallosilicate ECR-34, which requires a mixture of alkali ions and tetraethyl ammonium ions as the structure-directing species. Although this material contains a one-dimensional pore structure featuring useful 18-membered rings with a large diameter of $10.1 \AA^{[58]}$ it does not contain strongly acidic sites, limiting its application. Very recently, a mesoporous crystalline germanium oxide material was reported, with channels composed of an unusually large ring size of 30 , with a pore size of $12 \AA$ and $25 \AA$ cavities. ${ }^{[59]}$ Mixed organicinorganic framework species can adopt even more open structures, as was recently illustrated by the chromium terephthalate species MIL-101. This porous coordination compound consists of chromate trimers which are linked by terephthalate ligands to form 'super-tetrahedra', which are further organized to form two types of mesoporous cages with internal free diameters of 29 and $34 \AA$, respectively, and with windows of 12 and 14.5 by $16 \AA$, respectively. ${ }^{[60]}$

Synthetic approaches towards zeolites with large pore sizes may benefit from the introduction of small rings, as an experimental correlation between framework density and the smallest ring size within a structure has been discovered. ${ }^{[61]}$ Similar conclusions were drawn from computational studies by Zwijnenburg et al. ${ }^{[62]}$ who showed that the presence of a small amount of small rings (e.g. three-membered rings) may aid the stabilization of structures containing large pores and that synthetic efforts should be directed towards synthesizing building blocks containing three-membered rings. Such three-membered rings are known to exist in minerals such as phenakite and euclase, ${ }^{[63]}$ where Be atoms are present in these small rings. 
Annen et al. discovered that it was possible to substitute this toxic heteroatom for $\mathrm{Zn}$, and the first synthetic zincosilicate containing three-membered rings, VPI-7, was reported in $1991 .^{[64]}$ Rietveld refinement of this structure revealed the presence of a three-dimensional channel system comprising eight- and nine-membered rings. ${ }^{[65]}$ The three-membered rings are formed by $2 \mathrm{Si}$ and $1 \mathrm{Zn}$ atom, illustrating the need for atoms other than $\mathrm{Si}$ and $\mathrm{Al}$ to make small T-O-T angles possible. Cheetham et al. reported the preparation of a beryllosilicate, being the only one example of a framework containing three-membered rings combined with extra large pores (14-membered rings). ${ }^{[66]}$

The presence of three-membered rings has also been suggested to be advantageous in the quest for crystalline mesoporous materials. ${ }^{[50]}$ The lack of crystallinity, which is a general feature of this class of materials, has been ascribed to their low framework density. For a range of crystalline framework materials a correlation between the framework density and the size of the smallest ring size in the structure has been established. ${ }^{[61]}$ If this correlation is applied to mesoporous materials, which have typical void fractions $>0.5$, then the presence of three-membered rings becomes clearly beneficial in the quest to render these structures crystalline.

\subsubsection{HIERARCHICAL PORE ARCHITECTURES: COMBINING MICROPOROUS AND MESOPOROSITY}

The inherent limitations of the use of zeolites as catalysts, i.e. their small pore sizes and long diffusion paths, have been addressed extensively. Corma reviewed the area of mesopore-containing microporous oxides, ${ }^{[67]}$ with emphasis on extra-large pore zeolites and pillared-layered clay-type structures. Here we present a brief overview of different approaches to overcoming the limitations regarding the accessibility of catalytic sites in microporous oxide catalysts. In the first part, structures with hierarchical pore architectures, i.e. containing both microporous and mesoporous domains, are discussed. This is followed by a section on the modification of mesoporous host materials with nanometre-sized catalytically active metal oxide particles.

The introduction of a certain degree of mesoporosity into zeolite crystals in order to improve their diffusional properties is a straightforward idea with obvious benefits that has been explored for some time. Different strategies to introduce mesoporosity into zeolites have been reviewed in $2003,{ }^{[68]}$ and more recently by Pérez-Pariente et $a l .{ }^{[69]}$ The traditional way of generating mesoporous defects in a zeolite structure is by means of steam treatment. This treatment results in the selective removal of $\mathrm{Al}^{3+}$ from the framework, yielding so-called hydroxyl nests. Rearrangement of the structure often occurs, leading to healing of the structure in some places, and to the formation of larger cavities in other places. ${ }^{[70]}$ Although the additional mesoporosity thus created may be beneficial in terms of the overall diffusional properties of the solid, the decrease in crystallinity of the structure and the deposition of the removed material on the outer surface of the crystals are serious drawbacks. Acid leaching is an alternative method to remove framework 

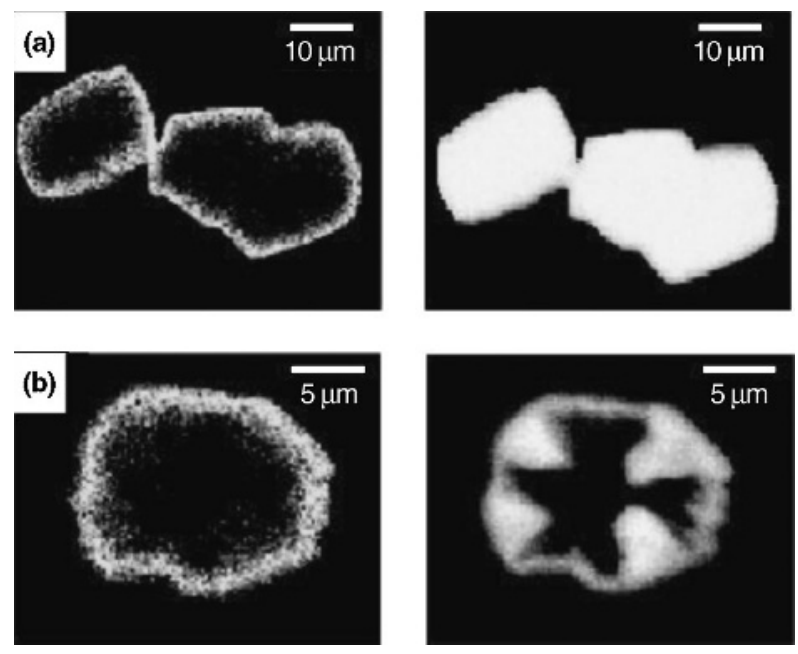

Figure 1.4 SEM-EDX images of polished nontreated (a) and alkaline-treated (b) ZSM-5 crystals. Desilication predominantly occurs in the core, where the Al concentration is lowest. Reproduced from Groen et al. ${ }^{[74]}$ by permission of American Chemical Society

aluminium. Mineral acids are routinely used for this purpose, which has as its main drawback the detrimental effect on the framework acidity (Al is removed or becomes partially extra-framework). Secondly, this technique is only applicable for high-alumina zeolites. Alkaline treatment of zeolites has been reported to dissolve siliceous species from the framework, thereby producing regular mesopores and leaving the microporous framework intact. ${ }^{[71,72]}$ The mechanism of alkaline desilication of ZSM-5 has been studied in detail and it was found that desilication is directed by framework $\mathrm{Al}^{3+}$, and an optimal $\mathrm{Si} / \mathrm{Al}$ range of 25-50 was established. Desilication results in mesopore surface areas (as analysed by $\mathrm{N}_{2}$ physisorption) as large as $200 \mathrm{~m}^{2} / \mathrm{g}$, coupled with a loss in micropore volume of less than $25 \% .{ }^{[73]}$ Large ZSM-5 crystals, with a high Al concentration near the outer surface of the crystals, could even be selectively desilicated in the core of the crystals, leading to hollow ZSM-5 crystals. This illustrates the influence of $\mathrm{Al}$ to $\mathrm{Si}$ extraction. Advanced three-dimensional TEM techniques were used to visualize the mesoporosity distribution (Figure 1.4). ${ }^{[74]}$

A different approach towards zeolites containing mesopores involves the incorporation of a template with mesoscopic dimensions into the zeolite synthetic procedure. Carbon spheres and carbon nanotubes have been used for this purpose, ${ }^{[75]}$ the latter with a typical diameter of $12 \mathrm{~nm}$ and several micrometres long. The synthesis of mesoporous silicalite-I, which is reported in this paper, simply involves the incorporation of the carbon nanotubes into the synthesis gel also containing TPAOH and TEOS. After combustion of the carbon template material, the product consists of single crystals with straight channels in the mesoporous size range penetrating the crystal (Figure 1.5). 


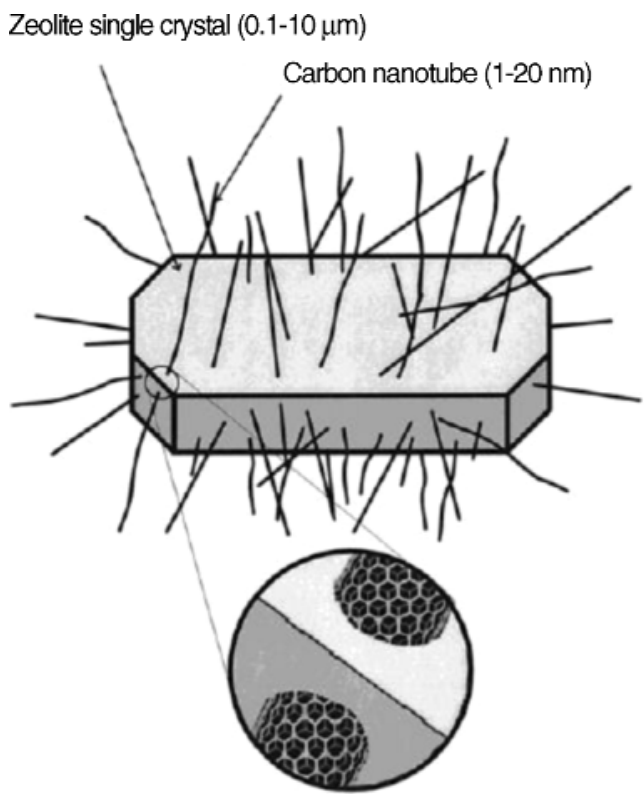

Figure 1.5 Schematic illustration of the synthesis principle for crystallization of mesoporous zeolite single crystals. The individual zeolite crystals partially encapsulate the nanotubes during growth. Selective removal of the nanotubes by combustion leads to formation of intracrystalline mesopores. Reproduced from Schmidt et al. ${ }^{[75]}$ by permission of American Chemical Society

Van de Water et al. reported that the introduction of small amounts of germanium into the synthesis gel of ZSM-5 changes its crystallization behaviour, resulting in increased mesoporosity. ${ }^{[76]}$ A possible explanation for the increased mesoporous and macroporous surface area is that germanium enhances the nucleation rate, thereby generating a larger number of very small primary crystals inside a synthesis-gel sphere. These primary crystals then aggregate immediately, resulting in an imperfect intergrowth with a high number of interfaces, which is the origin of the observed mesoporosity. The typical elongated prismatic crystal shape, characteristic of ZSM-5 (Figure 1.6a), is lost upon increasing the germanium content of the gel. Long, rectangular blocks are formed upon increasing the germanium content, which, in turn, form spherical aggregates with the crystallites being connected to each other in the centre of these spheres (Figure 1.6b).

Nitrogen physisorption of the Ge-ZSM-5 sample revealed a considerable contribution of mesopores to the total pore volume, accompanied by a drop in micropore volume of $20 \%$. In a study of the catalytic activity of these materials it was found that the increased mesoporosity of Ge-ZSM-5 had a beneficial effect on the catalytic activity in a series of acid-catalysed reactions. ${ }^{[77]}$ It was observed that the presence of germanium in the framework does not change the strength of the acid sites but, instead, decreases the extent of deactivation from coke residues formed upon reaction. The microporous domains only have short diffusional lengths, but the shape selectivity ascribed to the zeolitic channels is still fully 

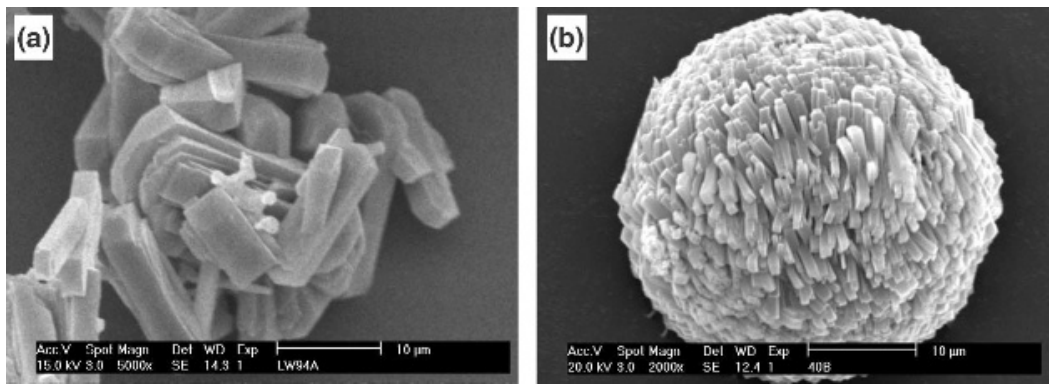

Figure 1.6 SEM picture of ZSM-5 (a) and Ge-ZSM-5 with a Ge/(Ge + Si) ratio of 0.17 (b). Reproduced from van de Water et al. ${ }^{[76]}$ by permission of American Chemical Society

effective. This was illustrated by the product distribution of the acetylation reaction of anisole, where it was reported that $>99 \%$ para-product was formed.

A completely different approach to combining zeolite micropores with mesoand even macroporosity has been published by $\mathrm{Li}$ and co-workers. ${ }^{[78]}$ They prepared self-supporting zeolite monoliths in a multi-step synthetic procedure. In the final material, micropores inside the zeolite nanocrystals $(30-40 \mathrm{~nm})$ are combined with a mesopore system formed by the packing of the nanoparticles, and a macropore system on the monolith level. Yet one step further towards improving the accessibility of the active sites of zeolites is to use two-dimensional zeolite layers, rather than three-dimensional frameworks, which would result in the ultimate reduction of the diffusion path length. Corma et al. reported on the delamination of a zeolite precursor with a clay-type layered structure, resulting in zeolite sheets with a layer thickness of around $25 \AA .{ }^{[79]}$ The layers consist of a hexagonal array of 'cups' with a 10-membered channel system running through the sheets. Clearly, all (framework-related) acid sites are accessible to substrate molecules which would be too large to fit in the channels of a corresponding three-dimensional material. Indeed, the authors showed that the catalytic cracking of $n$-decane over the delaminated material (ITQ-2) shows a similar rate constant compared with the MWW-type zeolite reference material, which represents a threedimensional analogue of the layered material. Interestingly, the products isolated from the reaction over ITQ-2 contain a smaller amount of gaseous products than those over MWW, indicating that fewer consecutive reaction steps occurred on ITQ-2. This is attributed to the shorter diffusion path into and out of ITQ-2. A large activity enhancement was found for ITQ-2 in cracking experiments involving vacuum gas oil, which was attributed to the better accessibility of the active sites in ITQ-2, compared with MWW (Figure 1.7).

The combination of micelle-forming species used in the preparation of mesoporous materials with silicate precursors of a variety of zeolites is a promising strategy to obtain mesoporous materials with zeolite-like acidity. ${ }^{[69]}$ Although some progress has been made in this field, it has yet to be proven that catalytic materials with improved performance can be obtained in this manner. Strong evidence of the presence of crystallinity in the mesopore walls, combined with an increased acidic 
(a)

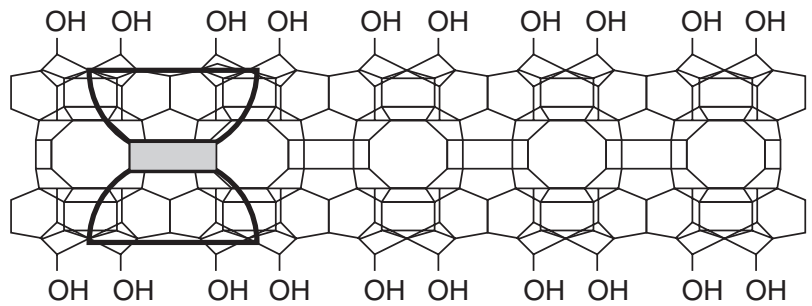

(b)

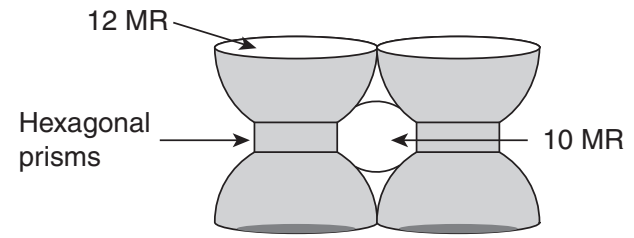

Figure 1.7 (a) Proposed structure for the ITQ-2 layer showing the characteristic 10-membered ring separating arrays of 'chalices' perpendicular to (001), with an artist's impression of one of the chalices included. (b) Artist's impression of two fused chalices, each made of two 'cups', connected by a nonshared six-membered ring at the bottom, and with a 12 -membered ring (12 MR) at their open top. The two fused chalices enclose a 10-membered ring (10 MR), which forms parts of the channel running between the cups inside the sheet. Reproduced from Corma et al. ${ }^{[79]}$ by permission of Macmillan Publishers Ltd

strength and catalytic activity and stability, has yet to be reported. In this respect, the assembly of so-called 'nanoslabs', as discussed in Section 1.1.2, into higher order structures is an exciting direction. One of the current theories regarding the early stages of zeolite framework formation comprises the aggregation of TEOS and TPA species into nm-sized nanoslabs (with dimensions of $1.3 \times 4.0 \times 4.0 \mathrm{~nm}$ ), which can be viewed as the building blocks from which the final zeolite structure is constructed. The organization of these building blocks into structures with mesoscopic dimensions would be a very attractive concept, indeed. However, the thickness of the crystalline nanoslabs $(1.3 \mathrm{~nm})$ is larger than the amorphous walls present in MCM-41 (1.0 nm), which would cause problems in view of the curvature of the channel walls. Despite this, the Leuven research group has very recently shown that it is possible to organize the nanometer-sized crystalline building blocks into hexagonally oriented so-called zeogrids and zeotiles. ${ }^{[80]}$ The assembly process of the zeolite blocks was interrupted by adding surfactant species such as cetyltrimethylammonium bromide, which is used as the micelle-forming species in the synthesis of M41S materials. This results in the organization of the nanoslabs into a mesoporous superstructure, where the walls are thought to consist of the microporous crystalline Silicalite-1 material.

Instead of introducing a degree of mesoporosity into a microporous catalyst, the problem can also be approached from the opposite direction. Kloetstra et al. reported the introduction of crystalline microporous domains inside mesoporous MCM-41 by the partial recrystallization of the pore walls. ${ }^{[81]}$ The mesoporous host can be regarded as the aluminium and silicon source for the zeolite crystallization. 
The starting material comprises Al-containing MCM-41, allowing for the formation of zeolite-like microporous domains after recrystallization of some of the MCM-41 pore wall material. These sites are expected to exhibit strongly acidic properties related to the now zeolitic framework Al sites. Secondly, the Al present in the MCM-41 parent material allows the introduction of $\mathrm{TPA}^{+}$cations, which is the template for ZSM-5, via an ion exchange step. On the basis of IR (the appearance of a band at $550 \mathrm{~cm}^{-1}$, characteristic of the five-membered rings present in the MFI structure) and ${ }^{27} \mathrm{Al} \mathrm{NMR}$ (an increase in the signal related to tetrathedrally coordinated $\mathrm{Al}$ ), it was concluded that part of the MCM-41 silicate material was, indeed, converted into 'embryonic' ZSM-5 domains. The catalytic activity was compared with that of the parent MCM-41 and it appeared that the modified material had a significantly higher activity in the cracking of cumene.

Zhang and co-workers reported partial conversion of a mesoporous starting material (SBA-15) into a mesoporous aluminosilicate with zeolitic characteristics in a so-called vapour phase transport method. ${ }^{[82]}$ In this process, Al is firstly introduced onto the mesoporous surface, followed by a filling of the mesopores with a carbonaceous species, and finally a partial recrystallization of aluminosilicate in the vapour of the SDA is conducted. The advantage of this method, compared with the hydrothermal recrystallization method of Kloetstra et al., lies in the fact that the mesopore structure collapses to a lesser extent as the crystallization is limited to the surface of the mesoporous precursor.

Nanometre-sized catalytic species may be dispersed into the pores of a mesoporous host material in order to maximize the available surface area of that catalytic species and to prevent sintering at elevated temperatures. In this respect, zeolite crystallites, metal oxide species and even nanometre-sized metal particles may be introduced into a mesoporous host. Zeolite Beta crystallites $(40 \mathrm{~nm})$ have been introduced by Waller et al. into the mesoporous silica host TUD-1 by blending preformed zeolite crystallites into the synthesis mixture of the mesoporous carrier. As such, the zeolite crystallites were 'frozen' in the TUD-1 synthesis mixture during its gelation step. ${ }^{[83]}$ The Zeolite Beta present in this composite material exhibits a higher activity in the cracking of $n$-hexane than does the equivalent amount of pure zeolite. The difference is ascribed to the fact that aggregation of the $40 \mathrm{~nm}$ particles occurs in the case of the pure zeolite, whereas in the composite material these particles are stabilized by the mesoporous host material. The accessibility of the active sites is improved in this way and the mesoporous pore system significantly reduced diffusion limitations on the reactant and product species of the reaction. Furthermore, the intergrowth region exhibits unusual acid sites, resulting from a twisted and strained surface, giving rise to high-energy surface siloxane two-rings which subsequently open to yield highly reactive silanols (as proven by in situ $\mathrm{NH}_{3}$ adsorption FTIR studies reported in the same paper). A similar one-pot synthesis approach was applied to introduce nanometre-sized oxide particles of metallic species, such as titanium, cobalt, iron, vanadium and molybdenum into the TUD-1 host. ${ }^{[84]}$ It was found that the particle size of these metal oxides was tunable by small changes in the preparation procedure, where the upper limit of their size is defined by the TUD- 1 mesopore size and the lower limit can be 
controlled by the concentration of the heteroatom species as well as the precise synthetic sequence (either inducing or avoiding heteroatom oxide particle formation). In some cases, i.e. in the case of titanium, even perfectly isolated tetrahedral metal atoms were present in the framework. The fate of the titanium species and its location could be tracked by in situ FTIR throughout the synthesis, thereby indirectly confirming the postulated formation mechanism of TUD-1. ${ }^{[85]}$ The immobilization of gold nanoparticles onto mesoporous silica and titania hosts in a one-pot synthesis has been achieved by adding phosphine-stabilized gold particles (with a diameter in the range of 5-10 nm) to the synthesis mixture of mesoporous silica or titania materials. ${ }^{[86]}$

\subsection{POTENTIAL OF POST-SYNTHESIS FUNCTIONALIZED MICROPOROUS AND MESOPOROUS SOLIDS AS CATALYSTS FOR FINE CHEMICAL SYNTHESIS}

\subsubsection{INTRODUCTION}

Whilst microporous and mesoporous materials in themselves can be catalytically active materials, as outlined in the previous sections, great potential lies in the possibility of their functionalization. Both homogeneous and heterogeneous catalysts have a great number of pros and cons, ranging from environmental and resource concerns (regarding the potential to recycle these materials), to the efficiency and effectiveness of the actual catalytic species. One area of mutual advancement for both these fields is in their combination, i.e. in the heterogenization of homogeneous catalysts. Microporous and mesoporous materials can provide the perfect supports for known homogeneous catalysts to facilitate this. In the following section the issues surrounding such composite materials are discussed.

The use, the development and the scope of individual microporous and mesoporous solids has been discussed in-depth in the previous section. The immobilization of further groups onto or into these hosts to provide the actual catalytic sites is a further sophistication in catalyst design. Incorporating catalytic species into the framework has disadvantages in that there are inherent structural irregularities, i.e. the preparation of a material with identical properties throughout in terms of the local environment of the catalytic sites cannot always be easily repeated. In contrast, immobilizing well-defined molecular catalysts provides identical single catalytic sites. ${ }^{[9,87]}$

There are several different approaches to fixing a molecular catalyst into a host material, some of these methods have been reviewed recently by On et al. ${ }^{[88]}$ in 2001 and by De Vos et al. ${ }^{[89]}$ Reviews from the perspective of chiral catalysis appeared in 2002 by Song and Lee, ${ }^{[90]}$ and in 2004 by Li, ${ }^{[91]}$ and noncovalently bound catalytic species on solid supports have been reviewed in 2004 by Horn et al ${ }^{[92]}$ This section is intended to complement these recent reviews and highlight as well as define the approaches encountered and to update some of the latest developments in this field. 


\subsubsection{COVALENT FUNCTIONALIZATION}

The covalent binding of a metal complex to a solid support is the most commonly applied technique of functionalizing a microporous or mesoporous material. In essence, this technique can be further categorized into two subsections: (1) grafting, this is the direct attachment of a metal complex to the silica framework of the material; and (2) tethering, whereby a spacer ('tether') is used between the wall of the material and the metal complex.

\section{Grafting of Metal Complexes}

The first example of the direct grafting of truly isolated metal species onto a periodic mesoporous silica framework was reported in 1995 by Maschmeyer et $a l .{ }^{[93]}$ This involved the reaction of a titanocene-derivative with the walls of MCM-41. After grafting the titanocene onto the surface of the mesoporous host, the ligand was removed by calcination, thereby revealing the catalytically active $\mathrm{Ti}^{4+}$ species (Figure 1.8). Prior to this publication, the nature of research was dominated by attempts to incorporate isolated titanium atoms into the framework of microporous and mesoporous materials. This paper reported the highest TOFs using Ticontaining mesoporous materials in the epoxidation of alkenes openly published at the time. Regeneration after eventual deactivation of the catalyst was achieved without loss of activity and these first results opened the path for greater exploration of these types of well-defined site-specific catalytic materials.

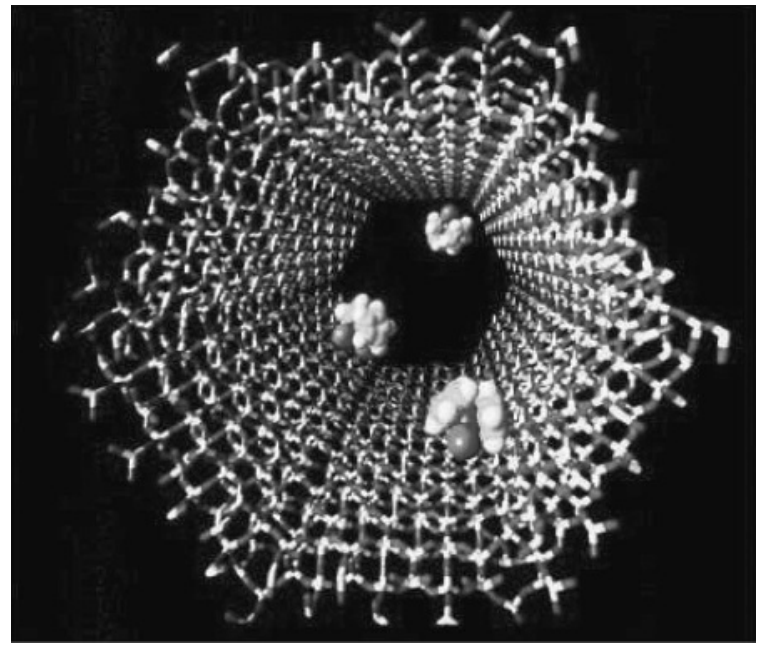

Figure 1.8 Computer-generated illustration of the accommodation (diffusion / adsorption) of molecules of titanocene dichloride inside a pore ( $30 \AA$ diameter) of siliceous MCM- 41 . For simplicity, none of the pendant $\mathrm{Si}-\mathrm{OH}$ (silanol) groups, that make it possible to graft organometallic moieties inside the mesoporous host, are shown. Reproduced from Maschmeyer et al. ${ }^{[93]}$ by permission of Macmillan Publishers Ltd 
Subsequently, a range of other metal species has been introduced onto the surfaces of mesoporous materials. These have often involved small metal complexes, the ligands of which were removed by calcination after being grafted onto the walls. ${ }^{[88]}$ Some recent examples of MCM-41 based materials are the Sn(IV) Lewis acids by Corma et al. ${ }^{[94]}$ vanadium-containing species by Singh et al.,${ }^{[95,96]}$ and a luminescent europium complex by Fernandes et al. ${ }^{[97]}$ Rhodium and molybdenum complexes have been given attention by Pillinger $e t$ al. in analogous procedures, whereby bimetallic acetonitrile complexes have been grafted onto MCM-41 ${ }^{[98,99]}$ These complexes have been shown to be sensitive to air, undergoing dissociation to create a mononuclear species in the case of Rh.

Mono- ${ }^{[100]}$ and bimetallic ${ }^{[101]}$ nanoparticles have been deposited inside the pores of mesoporous silicas in a two-step reaction. For example, the anionic metal carbonyl cluster $\left[\mathrm{Ru}_{6} \mathrm{C}(\mathrm{CO})_{16}\right]^{2-}$ [in the presence of bis(triphenylphosphino)iminium $\left(\mathrm{PPN}^{+}\right)$counterions] has been immobilized by incorporation into the pores of the host by impregnation. The carbonyl ligands are removed in a subsequent step by gentle thermolysis, yielding $\mathrm{nm}$-sized metal particles grafted onto the walls of the MCM-41 host material. In the case of a $\mathrm{Cu}-\mathrm{Ru}$ bimetallic cluster ${ }^{[102]}$ the bridging chloride ligands react with the surface silanols and covalent $\mathrm{Si}-\mathrm{O}-\mathrm{Cu}$ bonds were formed, anchoring the particle firmly to the surface. EXAFS revealed this anchoring process as well as the structural changes due to the removal of the carbonyl ligands (Figure 1.9). The very high dispersion of the metallic species thus obtained results in good activity in hydrogenation test reactions.

In comparison to the mesoporous materials, less research has been published on the functionalization of microporous materials by direct grafting (excluding various types of ion exchange). It has been stated that some of the newly modified mesoporous materials suffer from the adsorption of products and by-products onto the amorphous walls of the support structure. ${ }^{[103]}$ Microporous zeolitic

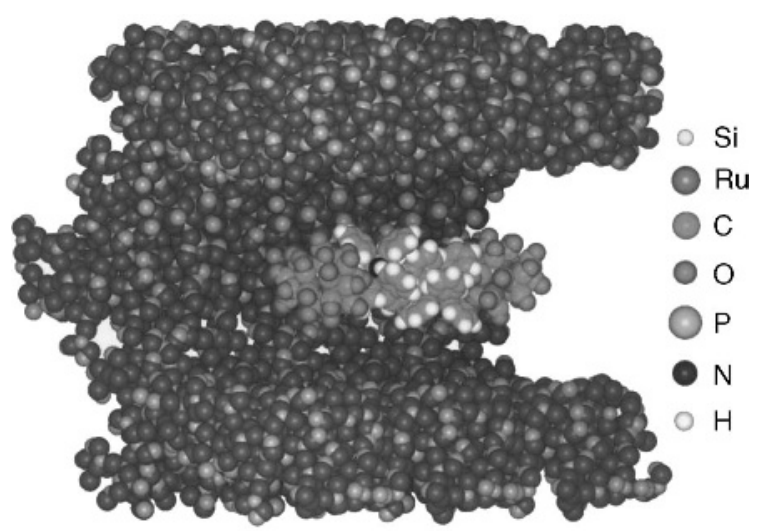

Figure 1.9 Van der Waals surface interactions of two $\left[\mathrm{H}_{2} \mathrm{Ru}_{10}(\mathrm{CO})_{25}\right]^{2-}$ and two $\mathrm{PPN}^{+}$ molecules packing along a single mesopore. Reproduced from Zhou et al. ${ }^{[100]}$ by permission of AAAS 


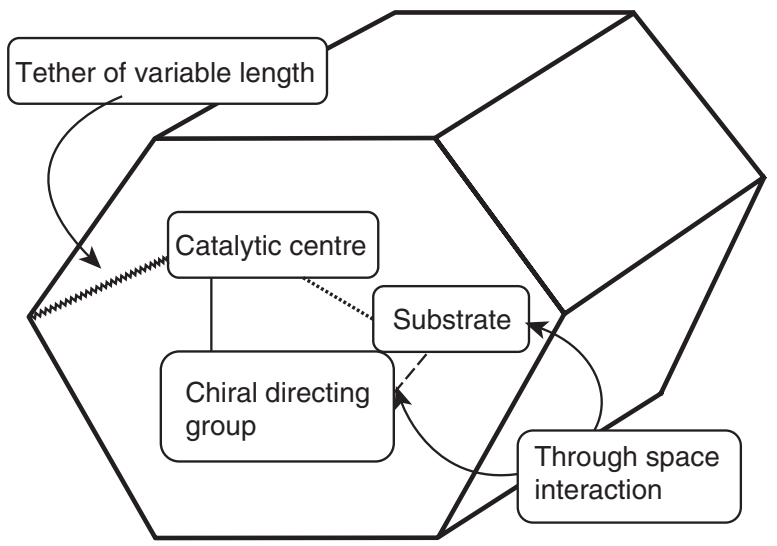

Figure 1.10 Schematic representation of the confinement concept. Reproduced from Thomas et al. ${ }^{[105]}$ by permission of Elsevier

materials possess better defined structures and may reduce the extent of such interactions: Sakthivel et al. reported the successful grafting of cyclopentadienyl molybdenum complexes onto H-zeolite Beta and H-zeolite-Y. ${ }^{[104]}$ However, even though the product adsorption issues were reduced, the relatively low selectivity combined with the poor TOF, leaching problems and deactivation of the catalytic species due to contamination by a by-product lead to the conclusion that the small pore size unduly affects the catalytic system in this case.

\section{Tethering of Metal Complexes}

The linking of a single-site transition metal complex catalyst to a mesoporous material via a spacer chain has become a popular method of heterogenizing a homogeneous complex. A schematic to describe this procedure is shown in Figure $1.10 .^{[105]}$ In this manner, the induction of desired chirality can also be introduced, using appropriate directing ligands attached to the active catalytic species. This results in catalytic materials that may be particularly interesting for the pharmaceutical industry and asymmetric catalysis is perhaps the biggest area of interest in the tethering of metal complexes to solid host materials. ${ }^{[90,105]}$ The tether itself can be of varied length linked to the catalytic complex either directly via the metal centre or via a ligand attached to that metal, or even, in particular cases, via both the ligand and the transition metal. ${ }^{[106]}$ The vast majority of publications following this approach involve mesoporous oxide host materials. In one of the first examples of this type of tethering, reported by Maschmeyer et al., MCM-41 was functionalized with glycine to provide an anchor point for a cobalt(III) complex. ${ }^{[107]}$ The Si-OH bonds were first functionalized with an alkyl bromide before the bromide end of the linker was reacted with the amine from glycine, allowing the carboxylic acid functional group to couple with the complex (Figure 1.11). 


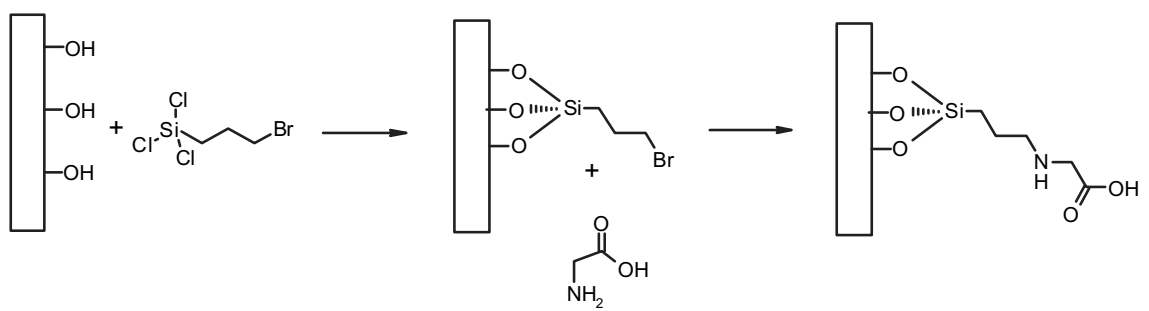

Figure 1.11 Functionalization of the MCM-41 surface silanols with an alkyl bromide and its subsequent derivatization with glycine

The results of the catalytic experiments show that the material with this linker performs much better, in terms of TOF, leaching of the catalytic species, catalyst lifetime and conversion, than a similar material without the linker. Another example of attaching a linker to provide a reactive carboxylic acid functional group upon which to couple a metal complex is provided by the work of Hultman et al. ${ }^{[108,109]}$ In this case, chiral dirhodium catalysts were immobilized through the coordination of the oxygen atoms of the carboxylic acid groups to the rhodium centres. The length of the linker was varied, with the three examples being an ethyl, an $n$-propyl and a (para-)phenyl group, i.e., obtaining five, six and seven atom spacers between the host wall and the active metal species. Unfortunately, the catalyst itself is large (13-19 $\AA$ ) compared with the pore size of the MCM-41 used initially (approximately $19 \AA$ ). Therefore, fine-tuning of the mesoporous host, i.e. use of TUD- 1 with much larger pore sizes, provided a more appropriate physical environment and an enhancement of the enantiomeric excess (ee) as compared with the homogeneous species could be determined. The catalytic results of these series of compounds indicate that improvements over the homogenous catalyst can result when immobilizing onto a solid support. In both these procedures, the silanols present on the external surface of the support were deactivated in order to (1) make sure that the complexes are attached only within the channels of the mesoporous material and (2) to avoid unwanted complex-complex interactions.

The most common type of functional group used to connect the support material to the catalytic species can broadly be defined as nitrogen-containing tethers. Besides amines, ${ }^{[106,110-112]}$ amides, ${ }^{[113]}$ pyridines ${ }^{[114,115]}$ and bipyridyls ${ }^{[16]}$ have been explored. ${ }^{[89]}$ Chiral $\mathrm{Mn}$ (salen) complexes have been frequently the catalyst of choice to be immobilized on various materials. ${ }^{[90]}$ The reason for this is the excellent reliability of this catalyst to facilitate the asymmetric epoxidation of alkenes. The most recent development of this type of catalyst (with respect to immobilization onto a solid mesoporous support) was the use of a phenoxy group, which coordinates with a $\mathrm{Mn}$ (salen) complex by displacing a chloride moiety with oxygen. $^{[117]}$ The inorganic host material is functionalized with (para-HO$\mathrm{Ph}) \mathrm{Si}(\mathrm{OEt})_{3}$, enabling coordination of the manganese ion by the phenoxy ligand. The active metal centre and the wall of the support are separated by six atoms. Catalytic results suggest a general improvement in the enantiomeric excess achieved 
in the epoxidation of $\alpha$-methylstyrene and $\operatorname{cis}$ - $\beta$-methylstyrene compared with the 'free' complex, however, yields were generally poorer. The first paper to illustrate the beneficial effect of confining a chiral catalyst inside a periodic mesoporous host regarding the regioselectivity and ee of the products was published by Johnson et al. in 1999. ${ }^{[10]}$ The system used consisted of a palladium complex containing a MCM41 surface-tethered, substituted ferrocene ligand. The catalytic results for the allylic amination of cinnamyl acetate showed conversion of approximately half of the starting material into the branched chiral product (the other $50 \%$ being converted into the straight-chained product), with up to $99 \%$ ee. In comparison, the homogeneous catalyst converted $79 \%$ of the starting material into only the straight-chained product. In this paper, the advantages of a well-defined, periodic mesoporous material (and its restrictive pores) in inducing chirality when compared with either a purely homogeneous catalyst, or a catalyst supported on a nonporous silica, are clearly illustrated.

A recent development of an amine tether was described by McKittrick et $a{ }^{[106,118]}$ In these publications, the linker effectively tethers both the $\mathrm{Zr} / \mathrm{Ti}$ catalytic centre and simultaneously holds the cyclopentadienyl ligand of the metal complex in place. This feature leaves the zirconium or titanium fully exposed to the reactants. Depending on the method of synthesis, it is possible to tailor the anchoring of a metal complex by either one or two amine tethers. In the first case, the primary amine linker is allowed to react with both the ligand and metal, in the latter case, one amine coordinates with the metal centre whilst another amine group reacts with the ligand. It was mentioned earlier that microporous zeolite materials make poor hosts for supporting catalytic transition metal species mainly due to their limited pore size. Corma et al. reported, very early on in this field of research rhodium complexes anchored onto a modified Y-zeolite via an amine tether with outstanding results. ${ }^{[119]}$ The 'supermicropores' (with a size range of 30-60 , i.e. mesopores) that are formed upon steam treatment of the zeolite USY host allow the introduction of such large entities, and this is, therefore, the first example of a tethered, albeit nonchiral, metal complex inside a mesoporous host. The catalytic test reactions showed no loss in hydrogenation activity, compared with the corresponding homogeneous catalyst, and no appreciable leaching of the complex after 10 cycles.

Moving onto other types of linkers, alkyl linkers have been developed by Sakthivel et al. ${ }^{[120]}$ An alkyl halide is usually the reactive species, where the halide is displaced by either the metal centre itself or by the ligand of the complex. An interesting example of the use of phosphine tethers is in the heterogenization of Grubbs' type catalysts. ${ }^{[121]}$ Here, the bound ruthenium complex allows the ROMP (ring opening metathesis polymerization) reaction to occur in aqueous conditions, a feature not possible with the homogeneous catalyst. Unfortunately, lower activities are observed, probably due to diffusion constraints. A notable use of a phosphine linker was reported by Shyu et al. ${ }^{[122]}$ who immobilized Wilkinson's catalyst $\left[\mathrm{Rh}\left(\mathrm{PPh}_{3}\right)_{3} \mathrm{Cl}\right]$ onto phosphinated MCM-41. The supported catalyst showed TOFs three times greater than the homogeneous catalyst, minimal leaching and maintained activity levels after 15 cycles. 


\subsubsection{NONCOVALENT IMMOBILIZATION APPROACHES}

\section{Noncovalently Bound Metal Complexes}

Evidence of immobilization of a metal complex via hydrogen bonding interactions between the ligand and the silanol groups of the oxidic support has been reported by Bianchini et al. ${ }^{[123]}$ Sulfonate groups on the end of a phosphine-based ligand formed strong non-covalent bonds with high surface area silica (Figure 1.12). These catalysts were shown to be promising in the hydrogenation of styrene and in the hydroformylation of 1-hexene. The activity in the hydroformylation reaction was even higher than in the corresponding homogeneous reaction, which is ascribed to the detrimental dimerization of the homogeneous Rh complex in solution. The high activity of the grafted complex is, therefore, ascribed to the presence of truly isolated $\mathrm{Rh}$ species. Leaching of the complex was not observed, as could be concluded from the fact that the catalytic results of the regenerated solid were unchanged, and that there was no evidence of catalysis in the filtrates taken from the first reactions. This method has not (yet) been further investigated for use on mesoporous materials. In 2000, the first example of this ion-exchange method as applied to mesoporous support materials was published by de Rege et al. ${ }^{[124]} \mathrm{A}$ triflate anion was used to immobilize a cationic rhodium complex onto MCM-41. The difference with the work of Bianchini and co-workers is that in their case the triflate moiety was part of the phosphine ligand, whereas in the MCM-41 based catalysts by de Rege et al. the strongly bound triflate anion (hydrogen bonding) was responsible for the anchoring of the cationic $\mathrm{Rh}$ complex. Other anions than triflate, such as the more lipophilic $\mathrm{B}\left[\mathrm{C}_{6} \mathrm{H}_{3}\left(\mathrm{CF}_{3}\right)_{2}-3,5\right]_{4}$, combined with the same $\mathrm{Rh}$ complex, were unable to cause the same effect. The supported complex displayed better catalytic activity (both in conversion and enantiomeric excess) than the unsupported complex. The newly heterogenized catalyst also proved to be recyclable and was stable to leaching in nonpolar solvents. Using exactly the same approach and anion, Raja et al. reported the immobilization of a range of chiral Rh phosphine complexes onto a set of inexpensive, commercially available silicas. ${ }^{[125]}$ The ee values of the asymmetric hydrogenation of methyl benzoylformate were found to increase upon decreasing pore size of the inorganic host, which reflects the beneficial effect of a constrained environment on the enantioselective performance of a chiral catalyst. This method is, in fact, a combination of two immobilization techniques: the triflate ion is hydrogen bonded to the surface hydroxyl groups, and the cationic metal complex is anchored onto this modified surface via an ionexchange step.

In this context, immobilization of metal complexes by means of ion exchange has been reported by Augustine et al. ${ }^{[126]}$ in 1999. In their study, polytungstic acid was used as anchor to affix a metal-containing catalytic complex onto a support material. It is thought that hydroxyl groups of the support react with the heteropoly acid. The (cationic) metal complex is anchored to the modified support via a strong ionic interaction, which is illustrated by the fact that no leaching of the complex was observed. The method appeared to be applicable to a range of support materials such as Montmorillonite K, carbon, alumina and lanthana. It was shown to be an 


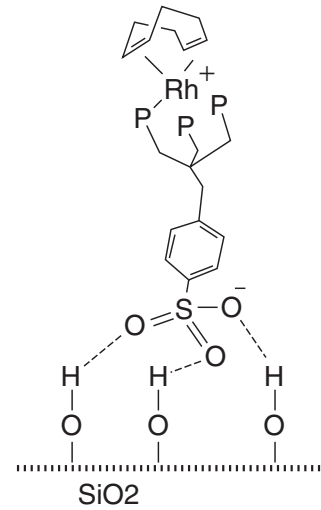

Figure 1.12 Noncovalently bound $\mathrm{Rh}(\mathrm{I})$ complex for hydroformylation, immobilized onto the silica surface via hydrogen bonding with the triflate moiety. Reproduced from Bianchini et al. ${ }^{[123]}$ by permission of American Chemical Society

effective means of anchoring a catalytic species without hampering its activity. Hölderich et al. reported the immobilization of rhodium diphosphine catalysts via ionic interactions with the aluminium-modified mesoporous materials Al-MCM-41 and Al-SBA-15. ${ }^{[127,128]}$ The presence of aluminium in these materials generates acidic protons on the surface, which can be readily exchanged with a cationic metal complex. In this way, the metal complexes interact directly with the negatively charged surface, and hence no modification of the support with an anchoring group is required. Comparing the catalytic results of the two materials, it seems that immobilization onto Al-MCM-41 is more beneficial in terms of activity. However, there is a discrepancy in the respective methods of alumination of the materials. Al-MCM-41 was formed with aluminium as an integral part of the synthetic process, whereas aluminium was incorporated into a SBA-15 framework in a postsynthesis reaction step. The use of yet another mesoporous material, Al-TUD-1, was explored in the research reported by Simons et al. ${ }^{[129,130]}$ The most notable part of these studies is the investigation into the effect of the catalyst in different solvents. The activity, enantioselectivity and the extent of $\mathrm{Rh}$ leaching all depend on the chosen solvent in asymmetric hydrogenation reactions using immobilized bidentate $\left\{\mathrm{Rh}^{\mathrm{I}}(\operatorname{cod})[(R, R)-\mathrm{DuPHOS}]\right\} \mathrm{BF}_{4}$ and $\left\{\mathrm{Rh}^{\mathrm{I}}(\operatorname{cod})[(S, S)-\mathrm{DiPAMP}]\right\} \mathrm{BF}_{4} \cdot{ }^{[130]}$ In terms of 'green' chemistry, the most interesting result was in the use of water as the solvent in a hydrogenation reaction using Rh-MonoPhos on Al-TUD-1. ${ }^{[129]}$ This catalyst was shown to achieve $95 \%$ ee (comparable with other solvents and the homogeneous catalyst) and $100 \%$ conversion levels, albeit with slightly longer reaction times. Even upon recycling of the catalyst, the results remained consistently good. The use of water as solvent allows the design of cascade reactions in which this immobilized 'chemo-catalyst' is coupled to a 'bio-catalyst', i.e. an enzymatic reaction system. ${ }^{[131]}$

Krijnen et al. reported on the noncovalent, nonionic immobilization of Tisilsesquioxanes onto MCM-41, as an epoxidation catalyst. ${ }^{[132]}$ An intriguing aspect 
of this particular research is the unaltered state of the original catalyst upon immobilization onto the support. The active catalytic species seems to be adsorbed onto the silica framework based on entropic gain (i.e. one large molecule displaces many surface-adsorbed small solvent molecules) with evidence to show that the cyclopentadienyl ligand of the Ti-silsesquioxane complex is unadulterated. It has been suggested that the ancillary cyclohexyl ligands of the complex interact with the surface of the MCM-41 pores (hydrophobic interactions), allowing the cyclopentadienyl group connected to the $\mathrm{Ti}$ centre to sit freely in the channel. The adsorption of the complex occurs rapidly and particularly so on Al-MCM-41 materials. ${ }^{[132]}$ However, functionalized Al-MCM-41 is prone to leaching and requires treatment with a silylating agent prior to catalysis to prevent this. ${ }^{[133]}$ The significantly quicker adsorption onto aluminium-doped MCM-41 suggests that, in addition to entropic considerations, polarity influences adsorption characteristics of the host material. XPS analysis suggests that this rapid adsorption prevents a homogeneous distribution of the complex inside the host, instead higher concentrations are found in the outer regions of the channels. The explanation being that the large silsesquioxane complex already adsorbed on a surface prevents another complex passing through the channel to deeper regions of the material. With the slower adsorption onto the all-silica species, the complex is allowed to travel further into the channel before adsorption takes place. This lower loading of the actual catalyst in the Al-MCM-41 mesopores explains the difference in TOF with the all-silica MCM-41 material. In an investigation into a 'tethered' approach to immobilizing a Ti-silsesquioxane complex, Smet et al. reported on the development of a (3-glycidyloxypropyl)trimethoxysilane linker between MCM-41 and titanium(IV) silsesquioxane. ${ }^{[134]}$ This approach however, offers no performance advantages over the pure-silica substrates described by Krijnen et al.

\section{Encapsulation of Metal Complexes}

Encapsulation covers a wide selection of methods to activate otherwise sedate microporous and mesoporous host materials. This heading describes the trapping of an active catalytic species within the pores of an inorganic support system. Along with the relatively simple notion of grafting metal oxides and clusters within the pores, there is also a more synthetically challenging method, namely the 'ship-in-abottle' approach (Figure 1.13). This approach has most often been associated with microporous materials as the smaller pore dimensions in these solids render this method most appropriate for the incorporation of a metal complex. The theory is that various substrates are applied separately to the inorganic support and that these assemble themselves (to create the catalyst) within the cages or pores of the support. The first example of this type of immobilized metal complex was reported by Herron in 1986, who formed a Co-salen complex inside the cages of zeolite Y by adding an excess of salen ligand to a sample of zeolite $\mathrm{Y}$ that had been ion exchanged with $\mathrm{Co}^{2+}$ ions. ${ }^{[135]}$ Since that time many examples of this encapsulation have been reported in the literature and the procedure is well described in a paper by Fukuoka et al., where special attention is given to the synthesis of platinum 


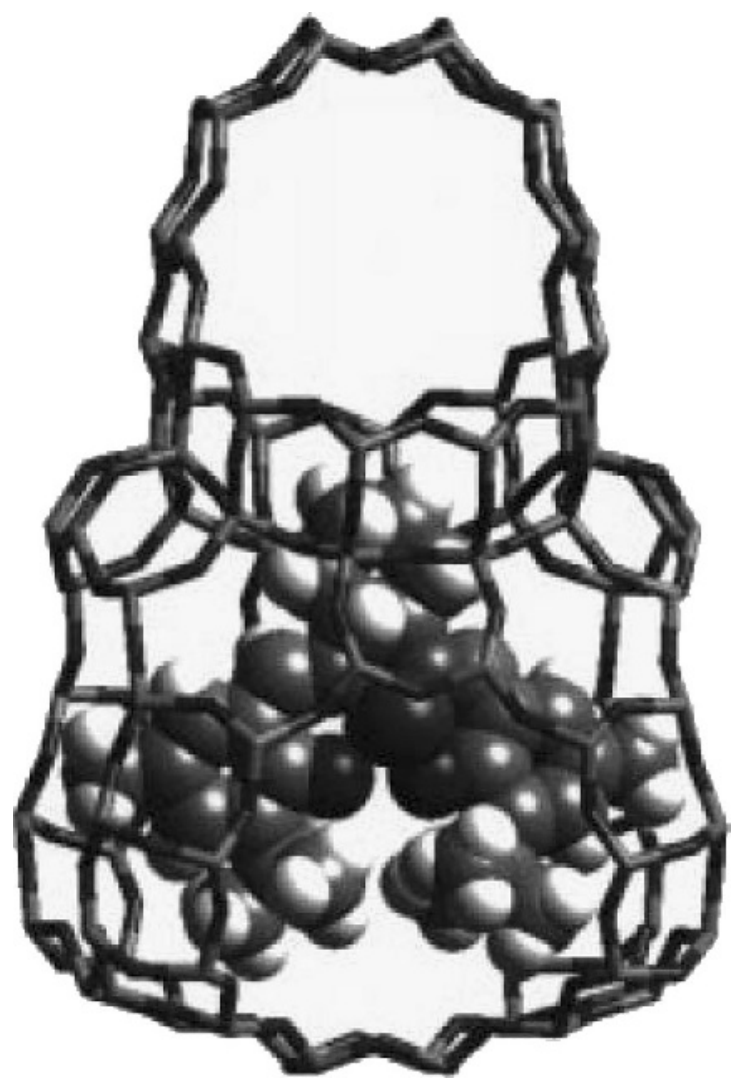

Figure 1.13 The 'ship-in-a-bottle' concept: view of Mn(III)-salen inside the cavity of zeolite EMT. Reproduced from Ogunwumi and Bain ${ }^{[138]}$ by permission of Royal Society of Chemistry

carbonyl clusters within both microporous (zeolite NaY) and mesoporous (FSM-16) materials. ${ }^{[136]}$ The aim of this study was to synthesize nanometre-sized Pt particles inside these hosts. To this end, the support was impregnated with a Pt salt, which was in a subsequent reductive decarbonylation step converted into $\left[\mathrm{Pt}_{3}(\mathrm{CO})_{6}\right]_{n}{ }^{2-}$ inside $\mathrm{NaY}$, and $\left[\mathrm{Pt}_{15}(\mathrm{CO})_{30}\right]^{2-}$ inside FSM-16, respectively. The metal-carbonyl complexes were then converted to Pt nanoparticles with a size of less than $2 \mathrm{~nm}$. Intrazeolite assembly of manganese-trimethyl triazacyclononane (tmtacn) complexes inside zeolite $\mathrm{Y}$ supercages has been shown to yield a highly selective epoxidation catalyst. ${ }^{[137]}$ Similarly, Mn-salen complexes have been formed inside zeolite cavities and have been shown to be selective epoxidation catalysts. ${ }^{[138,139]}$

To avoid the limitations of the small apertures and cavities provided by zeolites, mesopores have been created inside zeolites X, Y and DAY ${ }^{[140]}$ By dealumination of the zeolite structure, mesoporous regions that are completely surrounded by micropores were obtained, and these intrazeolitic cavities were then used as the space in which to assemble metal complexes. The preparation of a cobalt-salen-5 complex provided a catalytic material that shows improvements in the conversion, 
the selectivity and the diastereomeric excess over the homogeneous catalyst in the stereoselective epoxidation of limonene and pinene. Furthermore, the compounds are reusable and not prone to leaching.

\subsubsection{SINGLE-SITE CATALYSTS INSPIRED BY NATURAL SYSTEMS}

The general objective for all functionalized porous oxide materials described in the previous sections is that so-called 'single-site' catalytic species were the aim. This should ultimately result in highly selective catalysts as the local environment around each catalytic centre is very similar to that of neighbouring sites. In fact, this is very similar to catalysts in biological systems, which also feature very similar catalytic sites (protein-folding temporarily changing the precise environment at any given instant). The high selectivity of these biocatalytic/enzymatic systems is achieved by creating sites with well defined geometrical constraints, making them only accessible to certain substrate species. The approach to take ideas from nature in the design of new catalysts has been reviewed in detail. ${ }^{[141]}$

Mesoporous materials, as discussed in previous sections, contain pores of appropriate size to accommodate a broad range of enzymes, which often have dimensions of less than $100 \AA$ in all three dimensions. ${ }^{[142]}$ The interaction between the inorganic host and the enzyme is ionic in most cases, where the protonated form of the enzyme is attached to the negatively charged silica surface. In this way minimal or even no structural reorganization of the enzyme is required, resulting in comparable activities to the free enzyme species. Enzymes have also been grafted onto the surface of a foam-like silica, modified with aldehyde groups. Glucose oxidase was then coupled through its amine groups to the functional surface groups of the silica, although it appeared hard to control the degree of functionalization of the surface as such. ${ }^{[143]}$

The 'bio-inspired' molecular imprinting approach is based on the principle that the catalytic site should be shaped around a particular substrate, or alternatively, transition state species, in a similar manner as is the case in enzymes. When a template, which resembles the shape of the substrate, is used for the synthesis of the material, selectivity of the catalyst towards this particular substrate may be obtained after removal of the template. The catalytic reaction can only take place in this confined space, which resembles the way of action of enzymes. Most examples utilizing this technique involve polymerization of monomeric metal complexes containing a polymerizable group, such as styrene ${ }^{[144]}$ By copolymerizing with a cross-linking agent, e.g. ethylene glycol dimethacrylate, the final structure is expected to contain a high degree of cross-linking to make the structure rigid enough to retain its shape after removal of the template. Imprinted catalysts based on porous inorganic oxides are scarce. Corma and co-workers have reported on the synthesis and catalytic properties of ITQ-7, which contains 12-membered pores running in three dimensions. The template (or rather, SDA) used for its preparation was a quaternary ammonium species, prepared by a Diels-Alder reaction. When this catalyst, after removal of the template, was used in a Diels-Alder reaction 
involving a transition state similar in shape to that of the template used, it was found to be more active than other zeolite species with similar morphology. ${ }^{[141]}$

Iwasawa and co-workers used a $\mathrm{Rh}$-amine complex as a template to grow a silica network. ${ }^{[145]}$ Firstly, a $\mathrm{Rh}\left(\eta^{3}-\mathrm{C}_{3} \mathrm{H}_{5}\right) / \mathrm{SiO}_{2}$ (Aerosil 200) precursor was prepared, followed by a ligand exchange step where the $\mathrm{C}_{3} \mathrm{H}_{5}$ ligand was exchanged for $\alpha$-methylbenzylamine. The actual imprinting step was performed by reaction of this precursor with TEOS. After removal of the $\alpha$-methylbenzylamine template, a catalyst with selectivity for $\alpha$-methylstyrene, which has a similar structure to the template, was obtained.

In the zeolitic system, a significant amount of lattice energy stabilizes this imprinted transition state motif - a situation that reflects the situation in enzymes where hydrogen bonding controls the protein folding. This is a significant advantage over such imprints in amorphous supports like organic polymers and amorphous oxide surfaces where such stabilizing forces are largely absent, and it should lead to better overall performance.

In the following chapters the various applications, limitations and opportunities of the catalysts described in this chapter will be discussed.

\section{REFERENCES}

1. Coronado, E., Galan-Mascaros, J. R., Marti-Gastaldo, C., Palomares, E., Durrant, J. R., Vilar, R., Gratzel, M. and Nazeeruddin, M. K. Reversible colorimetric probes for mercury sensing. J. Am. Chem. Soc., 2005, 127, 12351-12356.

2. Gratzel, M. Solar energy conversion by dye-sensitized photovoltaic cells, Inorg. Chem., 2005, 44, 6841-6851.

3. Walcarius, A., Mandler, D., Cox, J. A., Collinson, M. and Lev, O. Exciting new directions in the intersection of functionalized sol-gel materials with electrochemistry, J. Mater. Chem., 2005, 15, 3663-3689.

4. Attia, A., Zukalova, M., Rathousky, J., Zukal, A. and Kavan, L. Mesoporous electrode material from alumina-stabilized anatase $\mathrm{TiO}_{2}$ for lithium ion batteries, J. Solid State Electrochem., 2005, 9, 138-145.

5. Coronado, E. and Palomares, E. Hybrid molecular materials for optoelectronic devices, J. Mater. Chem., 2005, 15, 3593-3597.

6. van Bekkum, H., Jacobs, P. A., Flanigen, E. M. and Jansen, J. C. Introduction to Zeolite Science and Practice. Elsevier, Amsterdam, 2001.

7. Lok, B. M., Cannan, T. R. and Messina, C. A. The role of organic molecules in molecular sieve synthesis, Zeolites, 1983, 3, 282-291.

8. Maschmeyer, T., Raimondi, M. E. and Seddon, M. Mesoporous molecular sieves. In The Encyclopedia of Materials: Science and Technology, K. H. J. Buschow et al. (eds). Elsevier, Oxford, 2001, Vol. 1, pp. 5342-5346.

9. Schuth, F. Engineered porous catalytic materials, Annu. Rev. Mater. Res., 2005, 35, 209-238.

10. Zones, S. I., Hwang, S. J., Elomari, S., Ogino, I., Davis, M. E. and Burton, A. W. The fluoride-based route to all-silica molecular sieves; a strategy for synthesis of new materials based upon close-packing of guest-host products, C. R. Chimie, 2005, 8, 267-282. 
11. Wagner, P., Nakagawa, Y., Lee, G. S., Davis, M. E., Elomari, S., Medrud, R. C. and Zones, S. I. Guest/host relationships in the synthesis of the novel cage-based zeolites SSZ-35, SSZ-36, and SSZ-39, J. Am. Chem. Soc., 2000, 122, 263-273.

12. Cundy, C. S. and Cox, P. A. The hydrothermal synthesis of zeolites: precursors, intermediates and reaction mechanism, Microporous Mesoporous Mater., 2005, 82, 1-78.

13. Burkett, S. L. and Davis, M. E. Mechanism of structure direction in the synthesis of Si-ZSM-5 - An investigation by intermolecular H-1-Si-29 CP MAS NMR, J. Phys. Chem., 1994, 98, 4647-4653.

14. Burkett, S. L. and Davis, M. E. Mechanism of structure direction in the synthesis of puresilica zeolites. 2. Hydrophobic hydration and structural specificity, Chem. Mater., 1995, 7, 1453-1463.

15. de Moor, P., Beelen, T. P. M., Komanschek, B. U., Diat, O. and van Santen, R. A. In situ investigation of Si-TPA-MFI crystallization using (ultra-) small- and wide-angle X-ray scattering, J. Phys. Chem. B, 1997, 101, 11077-11086.

16. Barrer, R. M., Baynham, J. W., Bultitude, F. W. and Meier, W. M., J. Chem. Soc., 1959, 195-208.

17. Ravishankar, R., Kirschhock, C. E. A., Knops-Gerrits, P. P., Feijen, E. J. P., Grobet, P. J., Vanoppen, P., De Schryver, F. C., Miehe, G., Fuess, H., Schoeman, B. J., Jacobs, P. A. and Martens, J. A. Characterization of nanosized material extracted from clear suspensions for MFI zeolite synthesis, J. Phys. Chem. B, 1999, 103, 4960-4964.

18. Kirschhock, C. E. A., Ravishankar, R., Verspeurt, F., Grobet, P. J., Jacobs, P. A. and Martens, J. A. Identification of precursor species in the formation of MFI zeolite in the TPAOH-TEOS- $\mathrm{H}_{2} \mathrm{O}$ system, J. Phys. Chem. B, 1999, 103, 4965-4971.

19. $\mathrm{Bu}, \mathrm{X}$. H., Feng, P. Y. and Stucky, G. D. Isolation of germanate sheets with threemembered rings: a possible precursor to three-dimensional zeolite-type germanates, Chem. Mater, 1999, 11, 3423-3424.

20. Anderson, M. W., Agger, J. R., Hanif, N. and Terasaki, O. Growth models in microporous materials, Microporous Mesoporous Mater., 2001, 48, 1-9.

21. Bosnar, S., Antonic, T., Bronic, J. and Subotic, B. Mechanism and kinetics of the growth of zeolite microcrystals. Part 2: Influence of sodium ions concentration in the liquid phase on the growth kinetics of zeolite A microcrystals, Microporous Mesoporous Mater., 2004, 76, 157-165.

22. Sankar, G., Thomas, J. M., Rey, F. and Greaves, G. N. Probing the onset of crystallization of a microporous catalyst by combined X-ray absorption spectroscopy and X-ray diffraction, J. Chem. Soc., Chem. Comm., 1995, 2549-2550.

23. Sankar, G. and Thomas, J. M. In situ combined X-ray absorption spectroscopic and X-ray diffractometric studies of solid catalysts, Top. Catal., 1999, 8, 1-21.

24. Grandjean, D., Beale, A. M., Petukhov, A. V. and Weckhuysen, B. M. Unraveling the crystallization mechanism of CoAPO-5 molecular sieves under hydrothermal conditions, J. Am. Chem. Soc., 2005, 127, 14454-14465.

25. Lewis, D. W., Catlow, C. R. A. and Thomas, J. M. Influence of organic templates on the structure and on the concentration of framework metal ions in microporous aluminophosphate catalysts, Chem. Mater., 1996, 8, 1112-1118.

26. Lewis, D. W., Willock, D. J., Catlow, C. R. A., Thomas, J. M. and Hutchings, G. J. De novo design of structure-directing agents for the synthesis of microporous solids, Nature, 1996, 382, 604-606.

27. Blasco, T., Corma, A., Diaz-Cabanas, M. J., Rey, F., Vidal-Moya, J. A. and ZicovichWilson, C. M. Preferential location of $\mathrm{Ge}$ in the double four-membered ring units of ITQ-7 zeolite, J. Phys. Chem. B, 2002, 106, 2634-2642. 
28. Corma, A. and Davis, M. E. Issues in the synthesis of crystalline molecular sieves: towards the crystallization of low framework-density structures, Chem Phys Chem, 2004, 5, 304-313.

29. Corma, A., Navarro, M. T., Rey, F., Rius, J. and Valencia, S. Pure polymorph C of zeolite beta synthesized by using framework isomorphous substitution as a structure-directing mechanism, Angew. Chem. Int. Ed., 2001, 40, 2277-2280.

30. Beck, J. S., Vartuli, J. C., Roth, W. J., Leonowicz, M. E., Kresge, C. T., Schmitt, K. D., Chu, C. T. W., Olson, D. H., Sheppard, E. W., McCullen, S. B. Higgins, J. B. and Schlenker, J. L. A new family of mesoporous molecular-sieves prepared with liquidcrystal templates, J. Am. Chem. Soc., 1992, 114, 10834-10843.

31. Kresge, C. T., Leonowicz, M. E., Roth, W. J., Vartuli, J. C. and Beck, J. S. Ordered mesoporous molecular-sieves synthesized by a liquid-crystal template mechanism, Nature, 1992, 359, 710-712.

32. Inagaki, S., Fukushima, Y. and Kuroda, K. Synthesis of highly ordered mesoporous materials from a layered polysilicate, J. Chem. Soc., Chem. Commun., 1993, 680-682.

33. Inagaki, S., Fukushima, Y. and Kuroda, K. Synthesis and characterization of highly ordered mesoporous material FSM-16, from a layered polysilicate, Stud. Surf. Sci. Catal., 1994, 84, 125-132.

34. Behrens, P. Voids in variable chemical surroundings: Mesoporous metal oxides, Angew. Chem. Int. Ed., 1996, 35, 515-518.

35. Vartuli, J. C., Schmitt, K. D., Kresge, C. T., Roth, W. J., Leonowicz, M. E., McCullen, S. B. Hellring, S. D., Beck, J. S., Schlenker, J. L., Olson, D. H. and Sheppard, E. W. Effect of surfactant silica molar ratios on the formation of mesoporous molecular-sievesinorganic mimicry of surfactant liquid-crystal phases and mechanistic implications, Chem. Mater., 1994, 6, 2317-2326.

36. Ulagappan, N. and Rao, C. N. R. Evidence for supramolecular organization of alkane and surfactant molecules in the process of forming mesoporous silica, Chem. Commun., 1996, 2759-2760.

37. Khushalani, D., Kuperman, A., Ozin, G. A., Tanaka, K., Garces, J., Olken, M. M. and Coombs, N. Metamorphic materials - restructuring siliceous mesoporous materials. Adv. Mater., 1995, 7, 842.

38. Cheng, C. F., Zhou, W. Z., Park, D. H., Klinowski, J., Hargreaves, M. and Gladden, L. F. Controlling the channel diameter of the mesoporous molecular sieve MCM-41, J. Chem. Soc., Faraday Trans., 1997, 93, 359-363.

39. Arafat, A., Jansen, J. C., Ebaid, A. R. and Vanbekkum, H. Microwave preparation of zeolite Y and ZSM-5, Zeolites, 1993, 13, 162-165.

40. Girnus, I., Jancke, K., Vetter, R., Richtermendau, J. and Caro, J. Large AlPO4-5 crystals by microwave-heating, Zeolites, 1995, 15, 33-39.

41. Lohse, U., Bertram, R., Jancke, K., Kurzawski, I., Parlitz, B., Loffler, E. and Schreier, E. Acidity of aluminophosphate structures. 2. Incorporation of cobalt into CHA and AFI by microwave synthesis, J. Chem. Soc., Faraday Trans., 1995, 91, 1163-1172.

42. $\mathrm{Wu}, \mathrm{C}$. G. and Bein, T. Microwave synthesis of molecular sieve MCM-41, Chem. Commun., 1996, 925-926.

43. Vartuli, J. C., Kresge, C. T., Leonowicz, M. E., Chu, A. S., McCullen, S. B. Johnsen, I. D. and Sheppard, E. W. Synthesis of mesoporous materials - liquid-crystal templating versus intercalation of layered silicates, Chem. Mater., 1994, 6, 2070-2077.

44. Zhao, X. S., Lu, G. Q. M. and Millar, G. J. Advances in mesoporous molecular sieve MCM-41, Ind. Eng. Chem. Res., 1996, 35, 2075-2090. 
45. Bagshaw, S. A., Prouzet, E. and Pinnavaia, T. J. Templating of mesoporous molecular sieves by nonionic polyethylene oxide surfactants, Science, 1995, 269, 1242-1244.

46. Zhao, D. Y., Feng, J. L., Huo, Q. S., Melosh, N., Fredrickson, G. H., Chmelka, B. F. and Stucky, G. D. Triblock copolymer syntheses of mesoporous silica with periodic 50 to 300 Angstrom pores, Science, 1998, 279, 548-552.

47. Wu, Y. Y., Cheng, G. S., Katsov, K., Sides, S. W., Wang, J. F., Tang, J., Fredrickson, G. H., Moskovits, M. and Stucky, G. D. Composite mesostructures by nano-confinement, Nature Materials, 2004, 3, 816-822.

48. Shan, Z., Jansen, J. C. and Maschmeyer, T. WO 00/15551, 2000.

49. Jansen, J. C., Shan, Z., Marchese, L., Zhou, W., van der Puil, N. and Maschmeyer, T. A new templating method for three-dimensional mesopore networks, Chem. Commun., 2001, 713-714.

50. Davis, M. E. Ordered porous materials for emerging applications, Nature, 2002, 417, 813-821.

51. Davis, M. E., Saldarriaga, C., Montes, C., Garces, J. and Crowder, C. VPI-5 - The 1st molecular-sieve with pores larger than 10 Angstroms, Zeolites, 1988, 8, 362-366.

52. Freyhardt, C. C., Tsapatsis, M., Lobo, R. F., Balkus, K. J. and Davis, M. E. A high-silica zeolite with a 14-tetrahedral-atom pore opening, Nature, 1996, 381, 295-298.

53. Lobo, R. F., Tsapatsis, M., Freyhardt, C. C., Khodabandeh, S., Wagner, P., Chen, C. Y., Balkus, K. J., Zones, S. I. and Davis, M. E. Characterization of the extra-large-pore zeolite UTD-1, J. Am. Chem. Soc., 1997, 119, 8474-8484.

54. Yoshikawa, M., Wagner, P., Lovallo, M., Tsuji, K., Takewaki, T., Chen, C. Y., Beck, L. W., Jones, C., Tsapatsis, M., Zones, S. I. and Davis, M. E. Synthesis, characterization, and structure solution of CIT-5, a new, high-silica, extra-large-pore molecular sieve, J. Phys. Chem. B, 1998, 102, 7139-7147.

55. Paillaud, J. L., Harbuzaru, B., Patarin, J. and Bats, N. Extra-large-pore zeolites with twodimensional channels formed by 14 and 12 rings, Science, 2004, 304, 990-992.

56. Corma, A., Diaz-Cabanas, M. J., Rey, F., Nicolooulas, S. and Boulahya, K. ITQ-15: The first ultralarge pore zeolite with a bi-directional pore system formed by intersecting 14-and 12-ring channels, and its catalytic implications, Chem. Commun., 2004, $1356-1357$.

57. Corma, A., Diaz-Cabanas, M., Martinez-Triguero, J., Rey, F. and Rius, J. A large-cavity zeolite with wide pore windows and potential as an oil refining catalyst, Nature, 2002, 418, 514-517.

58. Strohmaier, K. G. and Vaughan, D. E. W. Structure of the first silicate molecular sieve with 18-ring pore openings, ECR-34, J. Am. Chem. Soc., 2003, 125, 16035-16039.

59. Zou, X. D., Conradsson, T., Klingstedt, M., Dadachov, M. S. and O'Keeffe, M. A mesoporous germanium oxide with crystalline pore walls and its chiral derivative, Nature, 2005, 437, 716-719.

60. Ferey, G., Mellot-Draznieks, C., Serre, C., Millange, F., Dutour, J., Surble, S. and Margiolaki, I. A chromium terephthalate-based solid with unusually large pore volumes and surface area, Science, 2005, 309, 2040-2042.

61. Brunner, G. O. and Meier, W. M. Framework density distribution of zeolite-type tetrahedral nets, Nature, 1989, 337, 146-147.

62. Zwijnenburg, M. A., Bromley, S. T., Jansen, J. C. and Maschmeyer, T. Toward understanding extra-large-pore zeolite energetics and topology: a polyhedral approach, Chem. Mater., 2004, 16, 12-20.

63. Wyckoff, R. W. G. Crystal Structures. John Wiley \& Sons, Inc. New York, 1969. 
64. Annen, M. J., Davis, M. E., Higgins, J. B. and Schlenker, J. L. VPI-7 - The 1st zincosilicate molecular-sieve containing 3-membered T-atom rings, J. Chem. Soc., Chem. Commun., 1991, 1175-1176.

65. Rohrig, C., Gies, H. and Marler, B. Rietveld refinement of the crystal-structure of the synthetic porous zincosilicate VPI-7, Zeolites, 1994, 14, 498-503.

66. Cheetham, A. K., Fjellvag, H., Gier, T. E., Kongshaug, K. O., Lillerud, K. P. and Stucky, G. D. Very open microporous materials: from concept to reality, Stud. Surf. Sci. Catal., 2001, 135.

67. Corma, A. From microporous to mesoporous molecular sieve materials and their use in catalysis, Chem. Rev., 1997, 97, 2373-2419.

68. van Donk, S., Janssen, A. H., Bitter, J. H. and de Jong, K. P. Generation, characterization, and impact of mesopores in zeolite catalysts, Catal. Rev. - Sci. Eng., 2003, 45, 297-319.

69. Perez-Pariente, J., Diaz, I. and Agundez, J. Organizing disordered matter: strategies for ordering the network of mesoporous materials, C. R. Chimie, 2005, 8, 569-578.

70. Marcilly, C. R. Petrole et Techniques, 1986, 328, 12.

71. Ogura, M., Shinomiya, S. Y., Tateno, J., Nara, Y., Kikuchi, E. and Matsukata, H. Formation of uniform mesopores in ZSM-5 zeolite through treatment in alkaline solution, Chem. Lett., 2001, 882-883.

72. Ogura, M., Shinomiya, S. Y., Tateno, J., Nara, Y., Nomura, M., Kikuchi, E. and Matsukata, M. Alkali-treatment technique - New method for modification of structural and acid-catalytic properties of ZSM-5 zeolites, Appl. Catal., A, 2001, 219, 33-43.

73. Groen, J. C., Peffer, L. A. A., Moulijn, J. A. and Perez-Ramirez, J. Mechanism of hierarchical porosity development in MFI zeolites by desilication: the role of aluminium as a pore-directing agent, Chem. Eur. J., 2005, 11, 4983-4994.

74. Groen, J. C., Bach, T., Ziese, U., Donk, A., de Jong, K. P., Moulijn, J. A. and PerezRamirez, J. Creation of hollow zeolite architectures by controlled desilication of Al-zoned ZSM-5 crystals, J. Am. Chem. Soc., 2005, 127, 10792-10793.

75. Schmidt, I., Boisen, A., Gustavsson, E., Stahl, K., Pehrson, S., Dahl, S., Carlsson, A. and Jacobsen, C. J. H. Carbon nanotube templated growth of mesoporous zeolite single crystals, Chem. Mater, 2001, 13, 4416-4418.

76. van de Water, L. G. A., van der Waal, J. C., Jansen, J. C., Cadoni, M., Marchese, L. and Maschmeyer, T. Ge-ZSM-5: the simultaneous incorporation of Ge and Al into ZSM-5 using a parallel synthesis approach, J. Phys. Chem. B, 2003, 107, 10423-10430.

77. van de Water, L. G. A., van der Waal, J. C., Jansen, J. C. and Maschmeyer, T. Improved catalytic activity upon Ge incorporation into ZSM-5 zeolites, J. Catal., 2004, 223, 170-178.

78. Li, W. C., Lu, A. H., Palkovits, R., Schmidt, W., Spliethoff, B. and Schuth, F. Hierarchically structured monolithic silicalite-1 consisting of crystallized nanoparticles and its performance in the Beckmann rearrangement of cyclohexanone oxime, J. Am. Chem. Soc., 2005, 127, 12595-12600.

79. Corma, A., Fornes, V., Pergher, S. B., Maesen, T. L. M. and Buglass, J. G. Delaminated zeolite precursors as selective acidic catalysts, Nature, 1998, 396, 353-356.

80. Kirschhock, C. E. A., Kremer, S. P. B., Vermant, J., G. Van Tendeloo, Jacobs, P. A. and Martens, J. A. Design and synthesis of hierarchical materials from ordered zeolitic building units, Chem. Eur. J., 2005, 11, 4306-4313.

81. Kloetstra, K. R., van Bekkum, H. and Jansen, J. C. Mesoporous material containing framework tectosilicate by pore-wall recrystallization, Chem. Commun. 1997, 2281-2282.

82. Zhang, Y. W., Okubo, T. and Ogura, M. Synthesis of mesoporous aluminosilicate with zeolitic characteristics using vapor phase transport, Chem. Commun. 2005, 2719-2720. 
83. Waller, P., Shan, Z. P., Marchese, L., Tartaglione, G., Zhou, W. Z., Jansen, J. C. and Maschmeyer, T. Zeolite nanocrystals inside mesoporous TUD-1: a high-performance catalytic composite, Chem. Eur. J., 2004, 10, 4970-4976.

84. Hamdy-Saad, M. S. Functionalized TUD-1: synthesis, Characterization and (Photo-) catalytic Performance. Technische Universiteit Delft, The Netherlands, 2005.

85. Shan, Z., Gianotti, E., Jansen, J. C., Peters, J. A., Marchese, L. and Maschmeyer, T. Onestep synthesis of a highly active, mesoporous, titanium-containing silica by using bifunctional templating, Chem. Eur. J., 2001, 7, 1437-1443.

86. Moores, A., Goettmann, F., Sanchez, C. and Le Floch, P. Phosphinine stabilized gold nanoparticles; synthesis and immobilization on mesoporous materials, Chem. Commun. 2004, 2842-2843.

87. Thomas, J. M., Raja, R. and Lewis, D. W. Single-site heterogeneous catalysts, Angew. Chem. Int. Ed., 2005, 44, 6456-6482.

88. On, D. T., Desplantier-Giscard, D., Danumah, C. and Kaliaguine, S. Perspectives in catalytic applications of mesostructured materials, Appl. Catal., A, 2001, 222, 299-357.

89. De Vos, D. E., Dams, M., Sels, B. F. and Jacobs, P. A. Ordered mesoporous and microporous molecular sieves functionalized with transition metal complexes as catalysts for selective organic transformations, Chem. Rev., 2002, 102, 3615-3640.

90. Song, C. E. and Lee, S. G. Supported chiral catalysts on inorganic materials, Chem. Rev., 2002, 102, 3495-3524.

91. Li, C. Chiral synthesis on catalysts immobilized in microporous and mesoporous materials, Catal. Rev. - Sci. Eng., 2004, 46, 419-492.

92. Horn, J., Michalek, F., Tzschucke, C. C. and Bannwarth, W. Non-covalently solid-phase bound catalysts for organic synthesis, Top. Curr. Chem., 2004, 242, 43-75.

93. Maschmeyer, T., Rey, F., Sankar, G. and Thomas, J. M. Heterogeneous catalysts obtained by grafting metallocene complexes onto mesoporous silica, Nature, 1995, 378, 159-162.

94. Corma, A., Navarro, M. T. and Renz, M. Lewis acidic Sn(IV) centers - grafted onto MCM-41 - as catalytic sites for the Baeyer-Villiger oxidation with hydrogen peroxide, J. Catal., 2003, 219, 242-246.

95. Shylesh, S. and Singh, A. P. Synthesis, characterization, and catalytic activity of vanadium-incorporated, -grafted, and -immobilized mesoporous MCM-41 in the oxidation, of aromatics, J. Catal., 2004, 228, 333-346.

96. George, J., Shylesh, S. and Singh, A. P. Vanadium-containing ordered mesoporous silicas: Synthesis, characterization and catalytic activity in the hydroxylation of biphenyl, Appl. Catal., A, 2005, 290, 148-158.

97. Fernandes, A., Dexpert-Ghys, J., Gleizes, A., Galarneau, A. and Brunel, D. Grafting luminescent metal-organic species into mesoporous MCM-41 silica from europium(III) tetramethylheptanedionate, Eu(thd)(3), Microporous Mesoporous Mater., 2005, 83, 35-46.

98. Pillinger, M., Nunes, C. D., Vaz, P. D., Valente, A. A., Goncalves, I. S., Ribeiro-Claro, P. J. A., Rocha, J., Carlos, L. D. and Kuhn, F. E. Immobilization of rhodium acetonitrile complexes in ordered mesoporous silica, Phys. Chem. Chem. Phys., 2002, 4, 3098-3105.

99. Pillinger, M., Goncalves, I. S., Lopes, A. D., Ferreira, P., Rocha, J., Zhang, G. F., Schafer, M., Nuyken, O. and Kuhn, F. E. Mesoporous silica grafted with multiply bonded dimolybdenum cations: XAFS analysis and catalytic activity in cyclopentadiene polymerization, Phys. Chem. Chem. Phys., 2002, 4, 696-702.

100. Zhou, W. Z., Thomas, J. M., Shephard, D. S., Johnson, B. F. G., Ozkaya, D., Maschmeyer, T., Bell, R. G. and Ge, Q. F. Ordering of ruthenium cluster carbonyls in mesoporous silica, Science, 1998, 280, 705-708. 
101. Shephard, D. S., Maschmeyer, T., Johnson, B. F. G., Thomas, J. M., Sankar, G., Ozkaya, D., Zhou, W. Z., Oldroyd, R. D. and Bell, R. G. Bimetallic nanoparticle catalysts anchored inside mesoporous silica, Angew. Chem. Int. Ed., 1997, 36, 2242-2245.

102. Shephard, D. S., Maschmeyer, T., Sankar, G., Thomas, J. M., Ozkaya, D., Johnson, B. F. G., Raja, R., Oldroyd, R. D. and Bell, R. G. Preparation, characterization and performance of encapsulated copper-ruthenium bimetallic catalysts derived from molecular cluster carbonyl precursors, Chem. Eur. J., 1998, 4, 1214-1224.

103. Sakthivel, A., Zhao, J., Hanzlik, M. and Kuhn, F. E. Heterogenization of CpMo(CO)(3)Cl on mesoporous materials and its application as olefin epoxidation catalyst, J. Chem. Soc., Dalton Trans. 2004, 3338-3341.

104. Sakthivel, A., Zhao, J. and Kuhn, F. E. Cyclopentadienyl molybdenum complexes grafted on zeolites - synthesis and catalytic application, Catal. Lett., 2005, 102, $115-119$.

105. Thomas, J. M., Maschmeyer, T., Johnson, B. F. G. and Shephard, D. S. Constrained chiral catalysts, J. Mol. Catal., A, 1999, 141, 139-144.

106. McKittrick, M. W., Yu, K. Q. and Jones, C. W. Effect of metallation protocol on the preparation and performance of silica-immobilized TiCGC-inspired ethylene polymerization catalysts, J. Mol. Catal., A, 2005, 237, 26-35.

107. Maschmeyer, T., Oldroyd, R. D., Sankar, G., Thomas, J. M., Shannon, I. J., Klepetko, J. A., Masters, A. F., Beattie, J. K. and Catlow, C. R. A. Designing a solid catalyst for the selective low-temperature oxidation of cyclohexane to cyclohexanone, Angew. Chem. Int. Ed., 1997, 36, 1639-1642.

108. Hultman, H. M., de Lang, M., Nowotny, M., Arends, I., Hanefeld, U., Sheldon, R. A. and Maschmeyer, T. Chiral catalysts confined in porous hosts. 1. Synthesis, J. Catal., 2003, 217, 264-274.

109. Hultman, H. M., de Lang, M., Arends, I., Hanefeld, U., Sheldon, R. A. and Maschmeyer, T. Chiral catalysts confined in porous hosts. 2. Catalysis, J. Catal., 2003, 217, 275-283.

110. Johnson, B. F. G., Raynor, S. A., Shephard, D. S., Maschmeyer, T., Thomas, J. M., Sankar, G., Bromley, S., Oldroyd, R., Gladden, L. and Mantle, M. D. Superior performance of a chiral catalyst confined within mesoporous silica, Chem. Commun., 1167-1168 (1999).

111. Thomas, J. M., Johnson, B. F. G., Raja, R., Sankar, G. and Midgley, P. A. Highperformance nanocatalysts for single-step hydrogenations, Acc. Chem. Res., 2003, 36, 20-30.

112. Choi, J. S., Kim, D. J., Chang, S. H. and Ahn, W. S. Catalytic applications of MCM-41 with different pore sizes in selected liquid phase reactions, Appl. Catal., A, 2003, 254, 225-237.

113. Abrantes, M., Gago, S., Valente, A. A., Pillinger, M., Goncalves, I. S., Santos, T. M., Rocha, J. and Romao, C. C. Incorporation of a (cyclopentadienyl)molybdenum oxo complex in MCM-41 and its use as a catalyst for olefin epoxidation, Eur. J. Inorg. Chem., 2004, 4914-4920.

114. Pruss, T., Macquarrie, D. J. and Clark, J. H. Cobalt-acetato complexes immobilised on PYPA-organomodified silica: a case study of different ways of immobilisation, J. Mol. Catal., A, 2004, 211, 209-217.

115. Gago, S., Zhang, Y. M., Santos, A. M., Kohler, K., Kuhn, F. E., Fernandes, J. A., Pillinger, M., Valente, A. A., Santos, T. M., Ribeiro-Claro, P. J. A. and Goncalves, I. S. Synthesis and characterization of a manganese(II) acetonitrile complex supported on functionalized MCM-41, Microporous Mesoporous Mater., 2004, 76, 131-136. 
116. Nunes, C. D., Pillinger, M., Valente, A. A., Goncalves, I. S., Rocha, J., Ferreira, P. and Kuhn, F. E. Synthesis and characterization of methyltrioxorhenium(VII) immobilized in bipyridyl-functionalized mesoporous silica, Eur. J. Inorg. Chem., 2002, 1100-1107.

117. Zhang, H. D., Xiang, S., Xiao, J. L. and Li, C. Heterogeneous enantioselective epoxidation catalyzed by $\mathrm{Mn}$ (salen) complexes grafted onto mesoporous materials by phenoxy group, J. Mol. Catal., A, 2005, 238, 175-184.

118. Yu, K., McKittrick, M. W. and Jones, C. W. Role of amine structure and site isolation on the performance of aminosilica-immobilized zirconium CGC-inspired ethylene polymerization catalysts, Organometallics, 2004, 23, 4089-4096.

119. Sanchez, F., Iglesias, M., Corma, A. and Delpino, C. New rhodium complexes anchored on silica and modified Y-zeolite as efficient catalysts for hydrogenation of olefins, J. Mol. Catal., 1991, 70, 369-379.

120. Sakthivel, A., Zhao, J., Hanzlik, M., Chiang, A. S. T., Herrmann, W. A. and Kuhn, F. E. Heterogenization of organometallic molybdenum complexes with siloxane functional groups and their catalytic application, Adv. Synth. Catal., 2005, 347, 473-483.

121. Melis, K., De Vos, D., Jacobs, P. and Verpoort, F. ROMP and RCM catalysed by $(\mathrm{R} 3 \mathrm{P})(2) \mathrm{Cl} 2 \mathrm{Ru}=\mathrm{CHPh}$ immobilized on a mesoporous support, J. Mol. Catal., A, 2001, $169,47-56$.

122. Shyu, S. G., Cheng, S. W. and Tzou, D. L. Immobilization of $\mathrm{Rh}(\mathrm{PPh} 3)(3) \mathrm{Cl}$ on phosphinated MCM-41 for catalytic hydrogenation of olefins, Chem. Commun. 1999, 2337-2338.

123. Bianchini, C., Burnaby, D. G., Evans, J., Frediani, P., Meli, A., Oberhauser, W., Psaro, R., Sordelli, L. and Vizza, F. Preparation, characterization, and performance of tripodal polyphosphine rhodium catalysts immobilized on silica via hydrogen bonding, J. Am. Chem. Soc., 1999, 121, 5961-5971.

124. de Rege, F. M., Morita, D. K., Ott, K. C., Tumas, W. and Broene, R. D. Non-covalent immobilization of homogeneous cationic chiral rhodium-phosphine catalysts on silica surfaces, Chem. Commun. 2000, 1797-1798.

125. Raja, R., Thomas, J. M., Jones, M. D., Johnson, B. F. G. and Vaughan, D. E. W. Constraining asymmetric organometallic catalysts within mesoporous supports boosts their enantioselectivity, J. Am. Chem. Soc., 2003, 125, 14982-14983.

126. Augustine, R., Tanielyan, S., Anderson, S. and Yang, H. A new technique for anchoring homogeneous catalysts, Chem. Commun. 1999, 1257-1258.

127. Wagner, H. H., Hausmann, H. and Hölderich, W. F. Immobilization of rhodium diphosphine complexes on mesoporous Al-MCM-41 materials: catalysts for enantioselective hydrogenation, J. Catal., 2001, 203, 150-156.

128. Crosman, A. and Hölderich, W. F. Selective hydrogenation over immobilized rhodium diphosphine complexes on aluminated SBA-15, J. Catal., 2005, 232, 43-50.

129. Simons, C., Hanefeld, U., Arends, I., Minnaard, A. J., Maschmeyer, T. and Sheldon, R. A. Efficient immobilization of Rh-MonoPhos on the aluminosilicate AlTUD-1, Chem. Commun., 2004, 2830-2831.

130. Simons, C., Hanefeld, U., Arends, I., Sheldon, R. A. and Maschmeyer, T. Noncovalent anchoring of asymmetric hydrogenation catalysts on a new mesoporous aluminosilicate: application and solvent effects, Chem. Eur. J., 2004, 10, 5829-5835.

131. Simons, C., Hanefeld, U., Arends, I., Sheldon, R. A. and Maschmeyer, T. Towards genuine cascade reactions: asymmetric synthesis using combined chemo-enzymatic catalysts, Top. Catal., in press. 
132. Krijnen, S., Mojet, B. L., Abbenhuis, H. C. L., Van Hooff, J. H. C. and Van Santen, R. A. MCM-41 heterogenized titanium silsesquioxane epoxidation catalysts: a spectroscopic investigation of the adsorption characteristics, Phys. Chem. Chem. Phys., 1999, 1, 361-365.

133. Krijnen, S., Abbenhuis, H. C. L., Hanssen, R., van Hooff, J. H. C. and van Santen, R. A. Solid-phase immobilization of a new epoxidation catalyst, Angew. Chem. Int. Ed., 1998, 37, 356-358.

134. Smet, P., Riondato, J., Pauwels, T., Moens, L. and Verdonck, L. Preparation and characterization of a titanium(IV) silsesquioxane epoxidation catalyst anchored into mesoporous MCM-41, Inorg. Chem. Commun., 2000, 3, 557-562.

135. Herron, N. A cobalt oxygen carrier in zeolite $\mathrm{Y}-$ a molecular ship in a bottle, Inorg. Chem., 1986, 25, 4714-4717.

136. Fukuoka, A., Higashimoto, N., Sakamoto, Y., Sasaki, M., Sugimoto, N., Inagaki, S., Fukushima, Y. and Ichikawa, M. Ship-in-bottle synthesis and catalytic performances of platinum carbonyl clusters, nanowires, and nanoparticles in microporous and mesoporous materials, Catal. Today, 2001, 66, 23-31.

137. De Vos, D. E., Meinershagen, J. L. and Bein, T. Highly selective epoxidation catalysts derived from intrazeolite trimethyltriazacyclononane-manganese complexes, Angew. Chem. Int. Ed., 1996, 35, 2211-2213.

138. Ogunwumi, S. B. and Bein, T. Intrazeolite assembly of a chiral manganese salen epoxidation catalyst, Chem. Commun. 1997, 901-902.

139. Sabater, M. J., Corma, A., Domenech, A., Fornes, V. and Garcia, H. Chiral salen manganese complex encapsulated within zeolite $\mathrm{Y}$ : a heterogeneous enantioselective catalyst for the epoxidation of alkenes, Chem. Commun., 1997, 1285-1286.

140. Schuster, C. and Holderich, W. F. Modification of faujasites to generate novel hosts for 'ship-in-a-bottle' complexes, Catal. Today, 2000, 60, 193-207.

141. Corma, A. Attempts to fill the gap between enzymatic, homogeneous, and heterogeneous catalysis, Catal. Rev. - Sci. Eng., 2004, 46, 369-417.

142. Hartmann, M. Ordered mesoporous materials for bioadsorption and biocatalysis, Chem. Mater, 2005, 17, 4577-4593.

143. Zhang, X., Guan, R. F., Wu, D. Q. and Chan, K. Y. Enzyme immobilization on aminofunctionalized mesostructured cellular foam surfaces, characterization and catalytic properties, J. Mol. Catal., B, 2005, 33, 43-50.

144. Polborn, K. and Severin, K. Molecular imprinting with an organometallic transition state analogue, Chem. Commun. 1999, 2481-2482.

145. Tada, M., Sasaki, T. and Iwasawa, Y. Design of a novel molecular-imprinted Rh-amine complex on $\mathrm{SiO}_{2}$ and its shape-selective catalysis for alpha-methylstyrene hydrogenation, J. Phys. Chem. B, 2004, 108, 2918-2930. 